\title{
Functional and molecular neuroimaging of menopause and hormone replacement therapy
}

\author{
Erika Comasco $^{1,2 *}$, Vibe G. Frokjaer ${ }^{3}$ and Inger Sundström-Poromaa ${ }^{2}$ \\ ${ }^{1}$ Department of Neuroscience, Uppsala University, Uppsala, Sweden \\ 2 Department of Women's and Children's Health, Uppsala University, Uppsala, Sweden \\ ${ }^{3}$ Department of Neurology, Center for Integrated Molecular Brain Imaging and Neurobiology Research Unit 6931, Copenhagen University Hospital, Copenhagen, \\ Denmark
}

\section{Edited by:}

Belinda Pletzer, University of

Salzburg, Austria

Reviewed by:

Roberta Brinton, University of

Southern California, USA

Meir Steiner, McMaster University,

Canada

\section{*Correspondence:}

Erika Comasco, Department of

Neuroscience, Uppsala Biomedical

Center (BMC), Uppsala University,

Husargatan 3, Box 593, Uppsala 751

24, Sweden

e-mail: erika.comasco@neuro.uu.se
The level of gonadal hormones to which the female brain is exposed considerably changes across the menopausal transition, which in turn, is likely to be of great relevance for neurodegenerative diseases and psychiatric disorders. However, the neurobiological consequences of these hormone fluctuations and of hormone replacement therapy in the menopause have only begun to be understood. The present review summarizes the findings of thirty-five studies of human brain function, including functional magnetic resonance imaging, positron and single-photon computed emission tomography studies, in peri- and postmenopausal women treated with estrogen, or estrogen-progestagen replacement therapy. Seven studies using gonadotropin-releasing hormone agonist intervention as a model of hormonal withdrawal are also included. Cognitive paradigms are employed by the majority of studies evaluating the effect of unopposed estrogen or estrogen-progestagen treatment on peri- and postmenopausal women's brain. In randomized-controlled trials, estrogen treatment enhances activation of fronto-cingulate regions during cognitive functioning, though in many cases no difference in cognitive performance was present. Progestagens seems to counteract the effects of estrogens. Findings on cognitive functioning during acute ovarian hormone withdrawal suggest a decrease in activation of the left inferior frontal gyrus, thus essentially corroborating the findings in postmenopausal women. Studies of the cholinergic and serotonergic systems indicate these systems as biological mediators of hormonal influences on the brain. More, hormonal replacement appears to increase cerebral blood flow in several cortical regions. On the other hand, studies on emotion processing in postmenopausal women are lacking. These results call for well-powered randomized-controlled multi-modal prospective neuroimaging studies as well as investigation on the related molecular mechanisms of effects of menopausal hormonal variations on the brain.

Keywords: estrogens, fMRI, HRT, hormones, menopause, neuroimaging, PET, SPECT

\section{BACKGROUND}

The change in ovarian hormone levels to which the female brain is exposed during the menopausal transition is likely relevant for neurodegenerative diseases as well as psychiatric disorders. However, the effects of the peri- and postmenopausal estradiol level decline and hormone replacement therapy (HRT) on the brain have only begun to be understood (Mueller et al., 2014). Undeniably, a substantial lack of agreement on the beneficial vs. detrimental effect of HRT on mental health, and concerns about potential adverse effects exist (Henderson and Greicius, 2010). Thus, the prevention and clinical management of mental health problems during the menopausal transition suffers from uncertainty, which renders research in this field of outmost importance.

During the last two decades menopause researchers have opted for an intermediate phenotype-based approach to further the psychobiological dissection of menopausal hormonal transition and HRT effects on mental health. Indeed, intermediate phenotypes (e.g., biochemical, endocrine, anatomical, physiological) represent quantifiable basic biological or behavioral processes, which are expected to be closer to the genetic underpinning as well as to the psychological functions that might be affected (Meyer-Lindenberg and Weinberger, 2006; Rasetti and Weinberger, 2011). Neuroimaging techniques are certainly suitable tools for investigating potential intermediate phenotypes related to the neurobiological correlates of menopause and HRT.

The present review summarizes the findings of studies of human brain function (i.e., functional magnetic resonance imaging (fMRI), positron emission tomography (PET), single-photon emission computed tomography (SPECT/SPET), and magnetic resonance spectroscopy (MRS), of perimenopausal and postmenopausal women treated with unopposed estrogen or combined estrogen-progestagen replacement therapy. Additionally, studies of gonadotropin-releasing hormone $(\mathrm{GnRH})$ agonist 
treatment, as a pharmacological model of menopause, are also considered.

\section{STATE-OF-THE-ART}

To date, 35 functional neuroimaging studies have investigated brain function in peri- and postmenopausal women, and seven additional studies have used GnRH agonist intervention as a model of menopause (Tables 1-6). However, all studies are statistically under-powered since they include small samples, and they are also characterized by high heterogeneity in terms of study design. Differences regarding the study designs include: controlled randomization vs. cross-sectional trials, parallel vs. cross-over design, baseline vs. placebo control state, duration of the HRT use, unopposed estradiol vs. combined estrogenprogestagen therapy, route of administration and posology/dose of HRT, time between menopause and start of HRT ("critical window"), and chronological and reproductive age of the women. Dissimilarities regarding the neuroimaging data regard: neuroimaging techniques, neuropsychological paradigms within a cognitive domain, and statistical approaches for neuroimaging data processing and analysis. All together, these factors impeded any meta-analytical statistics.

\section{COGNITIVE FUNCTIONING}

The great majority of studies evaluating the effect of unopposed estrogen or combined estrogen-progestagen treatment on the menopausal and postmenopausal brain used cognitive paradigms (Tables 1, 2). Longitudinal, randomized controlled trial studies of the effects of estrogen treatment-three to twelve weeks in duration-indicated a higher activation of fronto-cingulate regions during cognitive functioning (Table 1 ), as assessed by fMRI using verbal, non-verbal and spatial working memory tasks. However, in spite of higher activation in fronto-cingulate regions, no differences in working memory performance were noted (Shaywitz et al., 1999; Joffe et al., 2006; Dumas et al., 2010). One sample of healthy postmenopausal women with an average of 7 years of prior estrogen use, and randomly assigned to a placebo or three-month hormonal treatment, showed an estradiol, memory load-dependent, effect on frontal activation, with a greater modulatory effect during the more difficult visual verbal working memory task (Dumas et al., 2010). During a verbal memory task, inferior frontal and posterior parietal regions, and during a spatial working memory task, frontal, posterior cingulate, and parietal regions, activation was greater in peri- and postmenopausal women receiving a three-week transdermal estradiol treatment compared to placebo (Joffe et al., 2006). Besides an increased and decreased inferior frontal lobule activation during storage of verbal and non-verbal material, respectively, a relatively large, randomized, double-blind, placebo-controlled, cross-over trial of estrogen treatment (for three weeks) in perimenopausal women indicated also a sharpened hemisphere encoding retrieval asymmetry (HERA) effect, with higher left-frontal hemisphere activation during encoding, and higher right-frontal hemisphere activation during retrieval in a working memory task (Shaywitz et al., 1999).

Moreover, two randomized controlled fMRI trials (Table 1), with cross-over designs, including ten healthy postmenopausal women each, suggested a counteractive effect of progestagens on memory, with increased, but to a lesser extent, prefrontal cortex activation after four weeks of combined estrogen-progestagen treatment vs. placebo (Smith et al., 2006; Persad et al., 2009). On the contrary, one parallel study of postmenopausal women did not observe any effect of six months of combined hormonal treatment in comparison with placebo on verbal fluency and mental rotation (Davison et al., 2013).

Results of cross-sectional neuroimaging studies on cognitive function are sparse (Table 2), and interpretation is limited by sample selection and study set-up discrepancies (Gleason et al., 2006; Berent-Spillson et al., 2010, 2012; Maki et al., 2011). Combined estrogen- or estrogen-progestagen treatment was associated with increased bilateral activation of the medial temporal lobe during encoding in postmenopausal women (Gleason et al., 2006). Activation in the medial temporal lobe during verbal and figural memory tasks differed between postmenopausal women who started HRT before menopause and never users, with a more pronounced decrease in parahippocampal gyrus and increase in left hippocampus activation in the HRT users during verbal recognition (Maki et al., 2011). Furthermore, HRT was associated with a better verbal memory performance, indicating a beneficial effect of HRT (Maki et al., 2011). A relatively large study found generalized increased brain activation upon a visual working memory task in women who had used estrogen, with or without progestagen addition, for more than 10 years, and begun HRT within two years of the menopause, compared to nonusers (Berent-Spillson et al., 2010). In the same sample, activation of the medial temporal lobes correlated positively with performance during a visual working memory task (Berent-Spillson et al., 2010). Moreover, differences between pre-, peri-, and postmenopausal women during a verbal, but not visual, memory task were found, independently of age, in frontal, prefrontal, and temporal cortices, with brain region activation being negatively correlated with estrogen levels (Berent-Spillson et al., 2012).

Finally, Maki and Resnick's longitudinal PET study provided evidence that estrogen treatment, with or without progestagen addition, modulates longitudinal changes in blood flow in brain regions implicated in cognitive function. Firstly, HRT users and non-users performing a verbal memory and a visual memory task showed, in a complex fashion, differences in the activation of regions subserving memory, such as the frontal lobe (Resnick et al., 1998). A smaller and overlapping sample was investigated two years later using the same study set-up. Greater activation of the temporal gyrus, hippocampus and insula regions, and the parahippocampal gyrus and inferior frontal gyrus, was observed during verbal and visual memory tasks, respectively, in long-term HRT users (more than two years) compared to non-users, thus indicating altered blood flow in brain areas subservicing memory in the presence of HRT (Maki and Resnick, 2000). However, in non-users other regions were also activated during the figural memory task compared to users (Maki and Resnick, 2000). Moreover, HRT was associated with better memory performance in the neuropsychological tests at both time points (Resnick et al., 1998; Maki and Resnick, 2000).

Notably, different components of the cognitive tasks contribute to the complexity of the many neuropsychological 


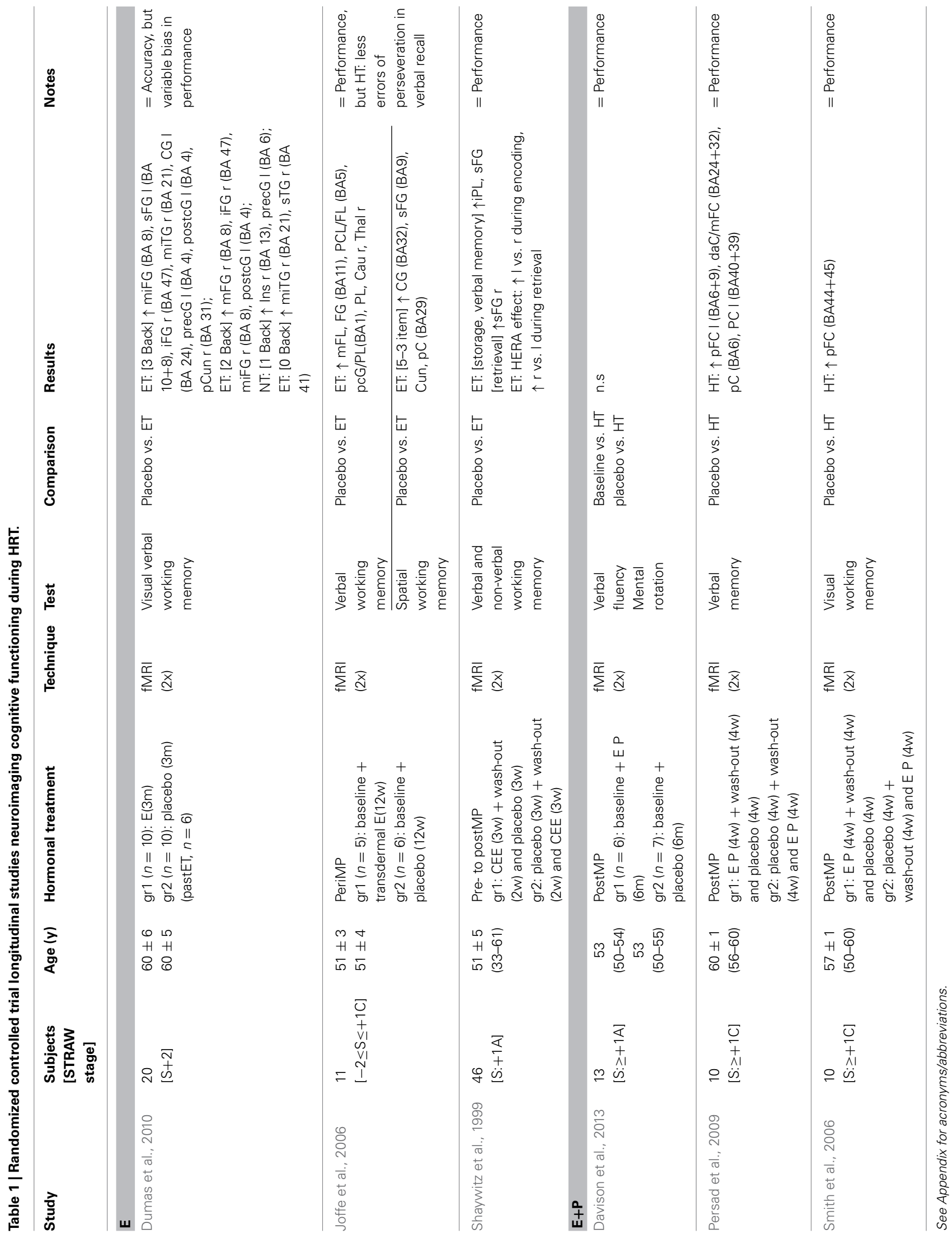




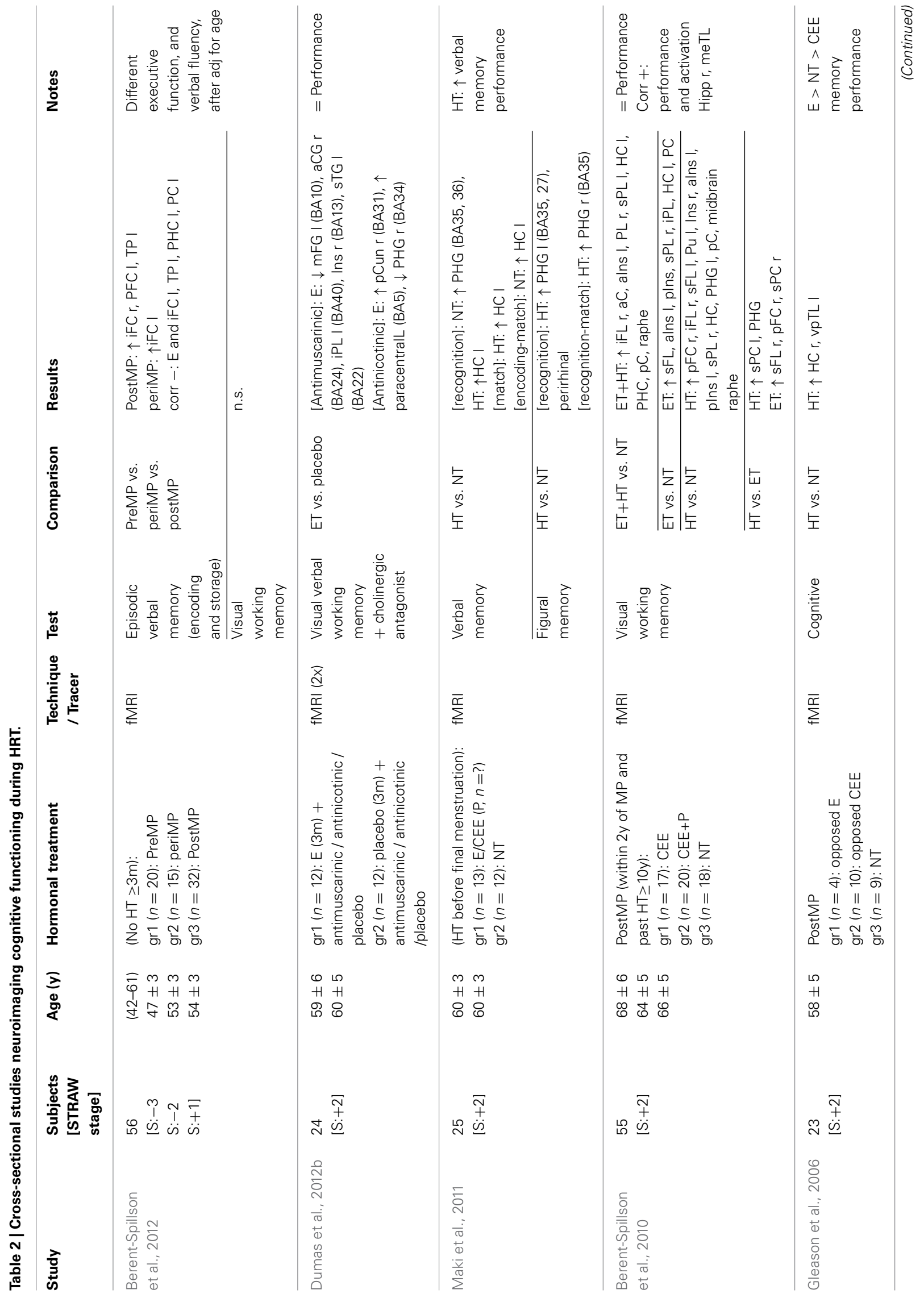


functions examined (Tables 1, 2). Functional domains of memory, such as executive function, attention, visuospatial processing, and language, are subserved by different brain circuits, which may have variable sensitivity to specific interventions (Gibbs, 2010). Memory tasks have been used predominantly to assess menopausal and HRT effects on cognitive functioning. Working memory, mainly subserved by the dorsal prefrontal cortex in humans, is a limited-capacity storage system to maintain and manipulate information over short time periods and is critical for many daily activities (Gibbs, 2010). The visual-verbal N-back test of working memory, used by Dumas et al. (2010), allows the examination of different working memory loads (i.e., 0-, 1-, $2-$, and 3- back conditions), from a condition of minimal memory load (0-) to one where subjects need to hold four letters in memory and update working memory as the next letter appears, alternatively seen as a cognitive stress model. Other verbal memory tasks, used by Shaywitz et al. (1999), Joffe et al. (2006), Persad et al. (2009), Berent-Spillson et al. (2012), Davison et al. (2013), involve learning and recall of word lists. Verbal memory has been suggested to be the most sensitive cognitive domain to the effect of HRT, and also a candidate proxy for dementia (Maki, 2013). The obvious discrepancy between imaging and cognition test results might be due to compensatory or deficient mechanisms, but also to differences in neuropsychological test performance within or outside the scanner. Noticeably estrogen did not seem to equally affect all cognitive domains, as shown by experimental studies (Gibbs, 2010).

fMRI detects changes in the blood oxygen level dependent (BOLD) signal, which is an index of the metabolic expenditures by neurons or glia during and immediately after the task. The BOLD signal is commonly accepted to reflect changes in neural activity, but interpretation should be cautious (Henderson and Greicius, 2010). Overall, it seems plausible to conclude that estrogen, alone or in combination with progestagens, positively affects brain activation during memory processing in postmenopausal women (Tables 1, 2). Nevertheless the neural underpinnings of HRT effects on memory remain to be elucidated. The prefrontal cortex is of particular relevance for cognition, and the neural substrate of the estradiol-induced memory enhancement, possibly due to its sensitivity to the hormonal milieu. Future studies are needed to clarify whether HRT may lower the risk of Alzheimer's disease and protect against age-related declines in memory (Henderson and Greicius, 2010; Marjoribanks et al., 2012), as well as which duration and timing of HRT would be optimal (Daniel, 2013).

\section{Pharmacological menopause and cognitive functioning}

Gonadotropin-releasing hormone agonist (GnRHa) treatment has been used as a model for menopause to assess cognitive signatures in young women (Table 3). GnRH is produced by the hypothalamus and pulsatile secretion of GnRH causes the anterior pituitary to release follicle-stimulating hormone (FSH) and luteinizing hormone (LH). Continuous treatment with GnRHa, on the other hand, will result in suppressed gonadal hormone production and is commonly prescribed for endometriosis, advanced breast cancer, but also to facilitate and secure subsequent safe super-ovulation during assisted reproduction therapy. 


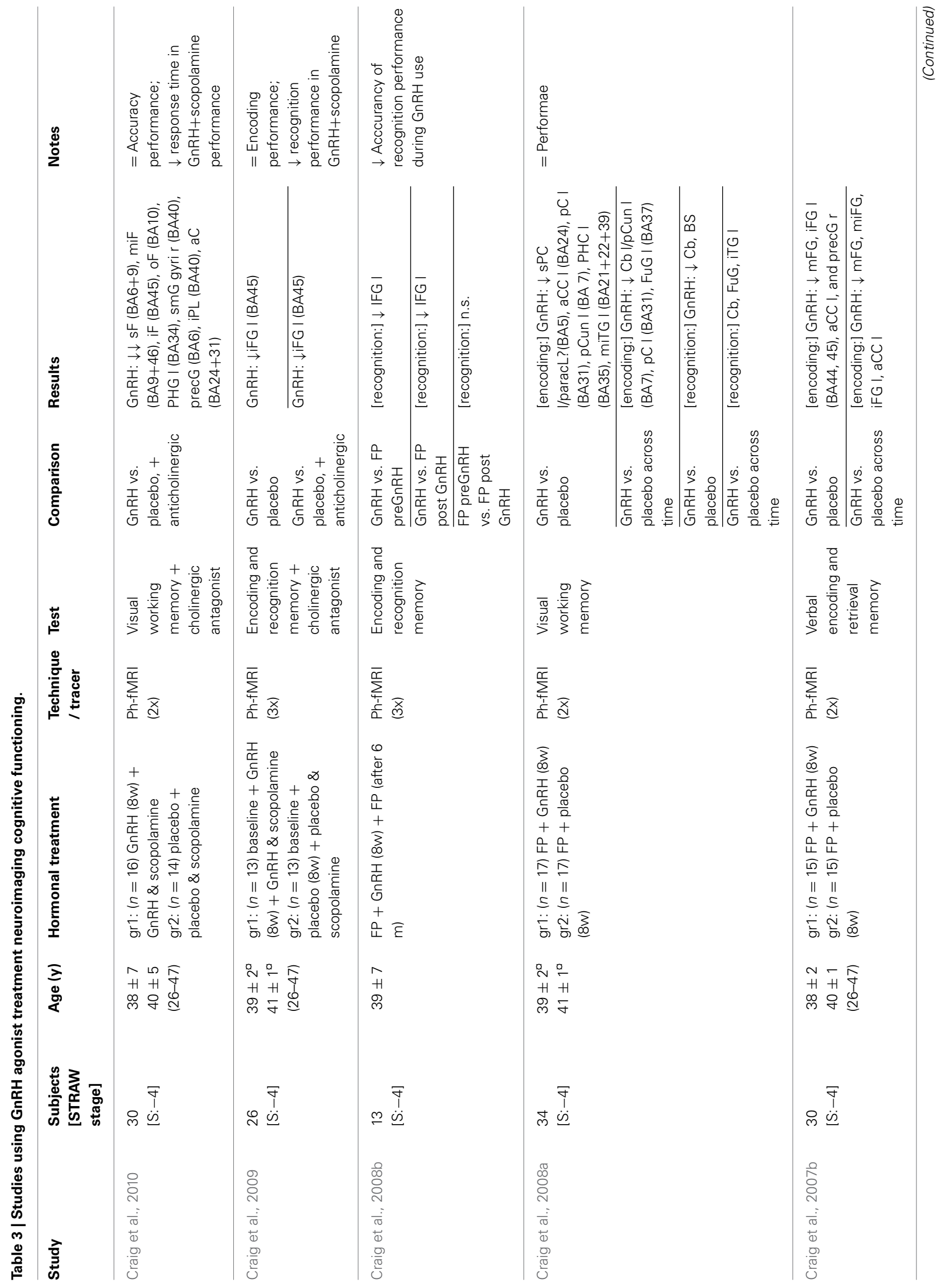


GnRHa treatment results in postmenopausal levels of endogenous estradiol by the second to fourth week of administration.

Berman and colleagues performed a seminal PET study using a GnRHa-induced hypogonadism model in 1997, and found higher blood flow in the inferior frontal gyrus during estrogen- or progestagen add-back to the GnRHa treatment (Berman et al., 1997). Three subsequent fMRI studies from Craig et al., though regionof-interest based, indicated a decreased activation of the same region, i.e., the left inferior frontal gyrus, during different memory tasks, after 8 weeks of pharmacological menopause (Craig et al., 2007b, 2008a,b). Moreover, this effect was demonstrated to be reversible as reflected at re-examination six months after discontinuation of GnRHa treatment (Craig et al., 2008b). Also, restored cognitive performance has been observed after GnRHa resolution (Craig et al., 2008b), or GnRHa discontinuation plus estrogen add-back treatment (Sherwin and Tulandi, 1996).

These results essentially corroborate the neuroimaging findings on working memory (i.e., visual, encoding and recognition, verbal and retrieval memory) in postmenopausal women (Tables 1-3). It is likely that these effects are not a direct consequence of the GnRHa but rather an indirect effect of reduced estradiol and progesterone levels in the brain. However, though the pseudo menopause produced by GnRHa is a powerful model, the impact of short-term ovarian suppression on cognition in young premenopausal women seems to be contradictory; in some cases strong (Sherwin and Tulandi, 1996; Grigorova et al., 2006), and in other cases only marginal (Rocca et al., 2014) or absent (Owens et al., 2002).

Taken together, though limited by a region-of-interest analysis approach, pharmacological challenge that induced acute ovarian hormone suppression in premenopausal women leads to attenuation of the brain activation pattern in the left inferior frontal gyrus (Table 3), a region sub-serving deep processing of to-belearned words, language and memory, typically activated during performance of executive function tasks in healthy women.

\section{NEUROBIOLOGICAL FUNCTIONING Neurotransmitter systems}

The changes in the hormonal milieu, and particularly in estrogen levels, during the menopausal transition period are likely to modulate neurotransmitter and neuroendocrine systems, thus modifying intermediate phenotypic patterns. Such neuropsycho-biological signatures may be involved in the mechanisms by which hormone changes may elicit cognitive dysfunction (Epperson et al., 2013), mental distress, and mental disorders (Hafner et al., 1993; Hafner, 2003; Freeman et al., 2006, 2014; Riecher-Rössler and Kulkarni, 2011). Most likely, the hormonal effects on brain function highlighted by fMRI studies are indirectly mediated through hormonal actions on neural sites serving multiple neurobiological systems (e.g., cholinergic, serotonergic, noradrenergic, and dopaminergic neurotransmitter system), as indicated by studies of primates showing estrogen-mediated neurotransmitter activities in the prefrontal cortex via alteration of cholinergic and monoaminergic innervations (Voytko et al., 2009), and emphasized by the widespread distribution of estrogen and progesterone receptors in the brain (Brinton et al., 2008; Wharton et al., 2012). The cholinergic, serotonergic, 


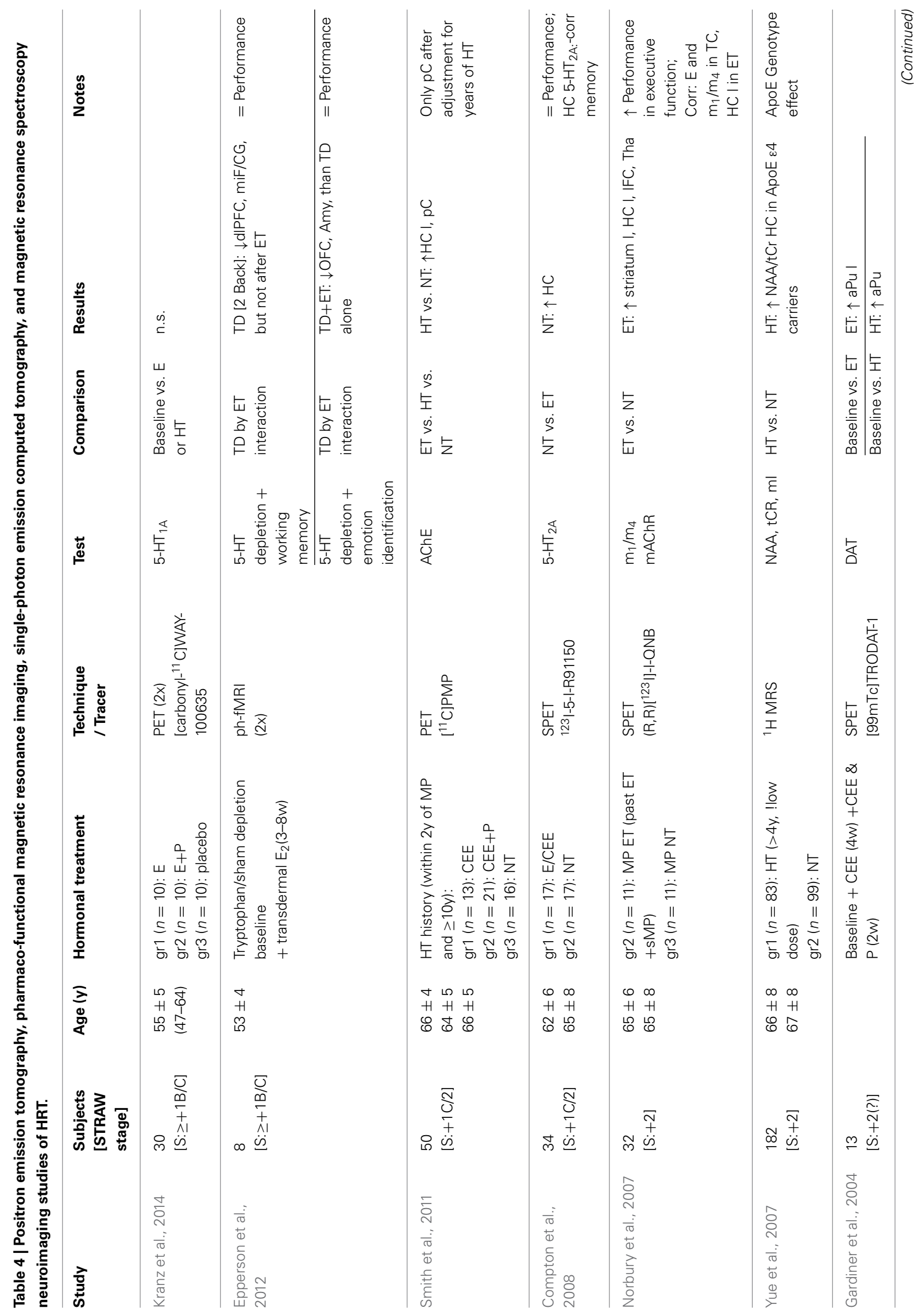




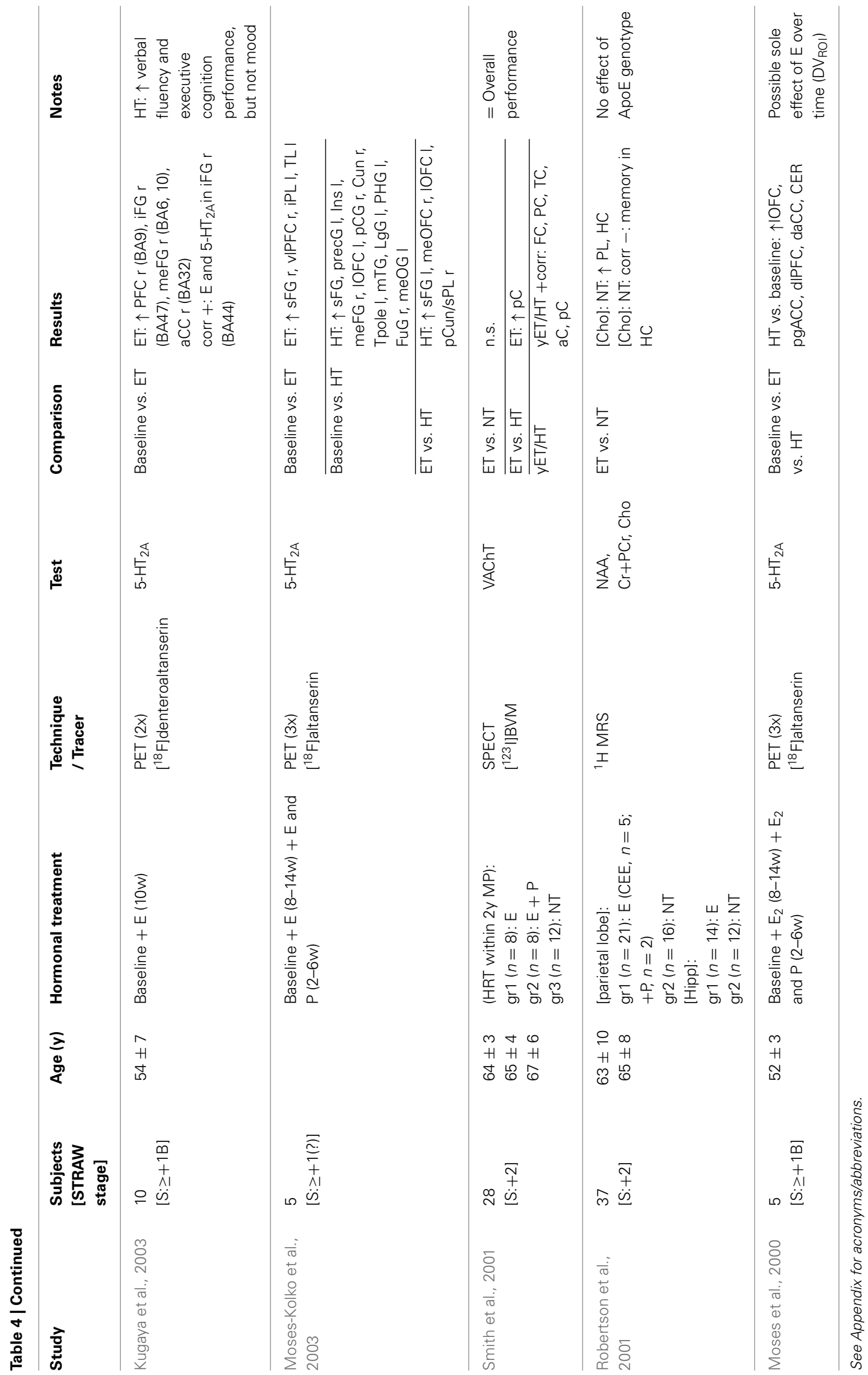


and dopaminergic systems have, in fact, been preliminarily investigated in relation to menopause, and seem to be biological mediators of positive effects of estrogens (Table 4) (Henderson and Greicius, 2010).

Acetylcholine (ACh). The central cholinergic system is critically involved in memory, learning and attention. Physiological aging is associated with reduction in cholinergic functional markers, such as choline acetyltransferase (ChAT), the enzyme synthetizing $\mathrm{ACh}$, but with a relative preservation of cholinergic cells and terminals. Alzheimer's disease, on the other hand, is associated with drastic reductions in ChAT and diffuse degeneration of cholinergic terminals as well as loss of acetylcholine nicotinic and muscarinic receptors $\mathrm{m} 1$ and $\mathrm{m} 4$ (Gibbs, 2010; Chopra et al., 2011). Both estrogen receptors have been identified in the nuclei of the human basal forebrain, which is the source of major cholinergic innervations to the cerebral cortex, hippocampus, and hypothalamus (Gibbs, 2010). Moreover, decreased cholinergic axon density in the prefrontal cortex was found in ovariectomized monkeys compared to estrogen-only or estrogen-progesterone treated animals, as well as to control animals (Kritzer and Kohama, 1999); and cholinergic fiber density in the prefrontal, but not parietal, cortex of ovariectomized monkeys is preserved after two years of estrogen treatment (Tinkler et al., 2004). Estrogen is indeed known to provide neurotrophic support, possibly through synergistic actions with the cholinergic system, and to regulate acetylcholine release, as supported by findings in rodents and non-human primates (Voytko et al., 2009; Daniel, 2013). Thus, while low menopausal estradiol levels are likely to diminish, HRT may enhance the survival or plasticity of cholinergic cells in postmenopausal women.

A cross-sectional PET study of women who initiated HRT within 2 years of menopause, and who had used it for more than 10 years, indicated a higher cholinergic activity $(8-10 \%)$, measured as acetylcholinesterase (AChE), the enzyme degrading $\mathrm{ACh}$ into choline and acetate, bilaterally in the posterior cingulate of combined estrogen-progestagen users compared to non-users (Smith et al., 2011). No effect on AChE was observed in the estrogen-only users compared to the non-users (Smith et al., 2011), suggesting a critical role of progesterone. On the contrary, cholinergic synaptic terminal density, assessed as binding of acethylcoline transporter (VAChT) in a SPECT crosssectional study, was $25 \%$ higher in the parietal cortex of women treated with estrogen-only, whom initiated HRT within 2 years of menopause, compared to combined hormone users (Smith et al., 2001). Moreover, VAChT binding in frontal, temporal and parietal cortices, as well as anterior and posterior cingulate regions, was positively correlated with duration of HRT use (Smith et al., 2001), consistent with a longer exposure to gonadal steroids being associated with trophic support of cholinergic neurons. Within the cholinergic system, receptors have also been investigated using SPECT in a cross-sectional study, and higher acethylcoline muscarinic receptor $\mathrm{m} 1 / \mathrm{m} 4$ binding was observed in postmenopausal estrogen users compared to women not receiving hormonal therapy, with greater density in the hippocampus, prefrontal cortex, striatum and thalamus (Norbury et al., 2007).
Additional proof of an interaction between estrogens and the cholinergic system has been given by two pharmaco-fMRI studies by Craig and colleagues (Table 3). This is in line with a protective effect of estrogen from the detrimental effects of anti-ACh challenge on attention found in humans (Dumas et al., 2006, 2008), monkeys (Voytko, 2002), and rodents (Sherwin and Henry, 2008). The former study demonstrated an additive effect of anticholinergic challenge with scopolamine on the decreased inferior frontal gyrus activation during encoding and recognition memory processing, in young women exposed to pharmacological menopause compared to placebo (Craig et al., 2009). The latter study, also using the cholinergic muscarinic receptor antagonist scopolamine, assessed visual working memory, and found more pronounced reduction of activation in frontal regions and parahippocampal gyrus in young women with pharmacologically induced menopause (Craig et al., 2010). Moreover, three-month estrogen treatment was shown to alter anticholinergic-related (i.e., both with the antimuscarinic drug scopolamine and with the antinicotinic drug mecamylamine) brain activation during a working memory task in postmenopausal women (Dumas et al., 2012b). Scopolamine challenge blocks muscarinic cholinergic receptors, and contributes to impairment of encoding of new memories; thus can be used as a pharmacological model of cognitive decline to investigate HRT-by-cholinergic interactive effects.

Altogether these studies reported an enhanced cholinergic neurotransmission in the presence of HRT, however discordantly regarding estrogen-only vs. estrogen-progestagens combined treatment (Tables 3, 4). The paucity and conflicting nature of findings regarding a modulatory effect of estrogen and/or progestagens on the effects of age on neural integrity in brain regions involved in cognitive function, on age-related memory decline, and on risk for Alzheimer's disease, impede any conclusion (Marjoribanks et al., 2012; Maki, 2013). Furthermore, the effect of menopausal stage at HRT initiation on cholinergic function and related hippocampus-mediated cognitive functioning needs to be explored (Daniel, 2013). For example short-, but not long-, term hormonal treatment has been shown to enhance cholinergic function in the prefrontal cortex and hippocampus of ovariectomized rats (Gibbs, 2000).

Serotonin (5-HT). Effects of menopausal changes in hormonal milieu and HRT may be partly mediated via the serotonin pathway, as experimental animal models indicate effects of ovarian hormones on the serotonergic system (Bethea et al., 2009; Voytko et al., 2009; Sanchez et al., 2013). Three longitudinal, but small, PET studies assessing the serotonin receptor $2 \mathrm{~A}\left(5-\mathrm{HT}_{2 \mathrm{~A}}\right)$ highlighted a general increased HRT-mediated binding potential in frontal and cingulate regions in postmenopausal women compared to baseline (Table 4) (Moses et al., 2000; Kugaya et al., 2003; Moses-Kolko et al., 2003). Consistently, 5- $\mathrm{HT}_{2 \mathrm{~A}}$ receptor availability in the prefrontal cortex was higher after two months of unopposed estrogen use in two independent samples of postmenopausal women (Kugaya et al., 2003; MosesKolko et al., 2003). Combined estrogen-progestagen treatment for one month was associated with increased $5-\mathrm{HT}_{2 \mathrm{~A}}$ binding potential in the frontal, precentral, cingulate, lingual, fusiform, 
parahippocampal and temporal gyrus, mainly in the left hemisphere, as well as in the insula, cuneus, and temporal pole in one study of five postmenopausal women (Moses-Kolko et al., 2003), and in the pregenual and dorso-anterior cingulate cortex, dorsolateral and lateral orbito prefrontal cortex, bilaterally, based on a region-of-interest approach, in another study of five postmenopausal women (Moses et al., 2000). Further support for a positive coupling between absolute levels of estradiol and global $5-\mathrm{HT}_{2 \mathrm{~A}}$ receptor availability comes from a large cross-sectional molecular imaging study in males (Frokjaer et al., 2010). Lastly, one SPECT study indicated lower hippocampal $5-\mathrm{HT}_{2 \mathrm{~A}}$ receptor binding to be coupled with estrogen treatment in long-term oophorectomized women, hypothesizing a down-regulation of post-synaptic receptors due to increased activity of the serotonergic pathway. However this result did not remain significant after correction for multiple comparison (Compton et al., 2008), and no firm conclusion can be derived from this finding due to the lack of correction for multiple comparisons and the low test-retest in the region of interest (Haugbol et al., 2007).

The mechanism by which HRT leads to a globally distributed $5 \mathrm{HT}_{2 \mathrm{~A}}$ binding increase is not fully understood. Yet, it potentially involves hormone-mediated genomic as well as neurotrophic mechanisms. Indeed, rodent work support that $5-\mathrm{HT}_{2 \mathrm{~A}}$ gene transcription is affected by estradiol. In ovariectomized rats, two-week estrogen plus progesterone, however not estrogen-only, treatment was associated with increased $5-\mathrm{HT}_{2 \mathrm{~A}}$ mRNA in the ventral hippocampus but not in the frontal cortex (Birzniece et al., 2002). Likewise, at the protein level, $5-\mathrm{HT}_{2 \mathrm{~A}}$ binding in the cerebral cortex of rats was increased after two-week estrogen-only, but not combined estrogen-progesterone, treatment (Biegon et al., 1983), while in blood of depressed women was decreased after four months of hormonal treatment (Wihlback et al., 2001). Additionally, reduced 5- $\mathrm{HT}_{2 \mathrm{~A}} \mathrm{mRNA}$ and binding in the frontal cortex of rats was restored after a two-week estrogen treatment (Cyr et al., 1998), suggesting that hormonal withdrawal per se also affects $5-\mathrm{HT}_{2 \mathrm{~A}}$ receptor numbers. All together these findings are in line with rat studies reporting direct effects of estradiol in maintaining $5-\mathrm{HT}_{2 \mathrm{~A}}$ receptor levels, both after castration of male animals and after ovariectomy in female animals (Sumner and Fink, 1997, 1998; Sumner et al., 1999, 2007). Testosterone, also increase $5-\mathrm{HT}_{2 \mathrm{~A}}$ receptor expression, however only when converted to estradiol locally by aromatase (Sumner and Fink, 1998), again highlighting that estradiol is the main driver of $5 \mathrm{HT}_{2} \mathrm{~A}$ responses to HRT.

A recent randomized placebo controlled study of postmenopausal women found no effect of 8 weeks of HRT, of neither estrogen-only nor combined estrogen-progestagen treatment, on 5- $\mathrm{HT}_{1 \mathrm{~A}}$ binding potential (Table 4) (Kranz et al., 2014). However, 5- $\mathrm{HT}_{1 \mathrm{~A}}$ receptor binding was negatively correlated at the whole brain level with progesterone, but not estradiol, serum concentrations in postmenopausal women (Stein et al., 2014). Interestingly, an animal model of surgical menopause indicated a time-dependent effect of estrogen on this autoreceptor, with onemonth, but not five-months, estrogen treatment being associated with decreased $5-\mathrm{HT}_{1 \mathrm{~A}}$ receptor protein expression in ovariectomized monkeys in the dorsal raphe nucleus, which is source of serotonergic neurons within CNS (Henderson and Bethea,
2008). However, combined estrogen plus progesterone administration decreased $5-\mathrm{HT}_{1 \mathrm{~A}}$ receptor protein expression at both time points (Henderson and Bethea, 2008). Also, $5-\mathrm{HT}_{1 \mathrm{~A}}$ receptor binding in the dorsal raphe nucleus has been shown to decrease after one month of treatment with either estrogen, progesterone, or a combination of both in ovariectomized monkeys ( $\mathrm{Lu}$ and Bethea, 2002). Thus, an enhanced time-dependent effect of HRT on serotonergic neurotransmission cannot be excluded.

Additionally, using a dietary tryptophan depletion challenge, by which serotonergic tonus can be lowered transiently, serotonin-by-estrogen interaction effects were found in a small fMRI study in relation to cognitive and emotional processing in early postmenopausal women (Table 4). When tryptophan depleted, non-users had reduced bilateral dorsal lateral prefrontal cortex and middle frontal/cingulate gyrus activation in comparison to estrogen-only treated women; while lowered orbitofrontal cortex and amygdala activation in relation to emotion identification was observed in the estrogen users (Epperson et al., 2012). However, no interactive effect was observed between tryptophan or tyrosine/phenylalanine depletion and estrogen treatment on emotional, behavioral, and cognitive performance in healthy postmenopausal women (Newhouse et al., 2008, 2010). Women exhibited increased stress-triggered negative mood and worsened cognitive performance after a three-month estrogen administration compared to placebo, independently of monoamine depletion (Newhouse et al., 2008, 2010).

Estrogen, alone or combined with progesterone, not only modulates serotonergic function at the level of neurotransmitter synthesis, turnover, release, and receptor, but has also a neuroprotective role on serotonin neurons, as indicated by studies of monkeys (Bethea et al., 2009). The serotonin system critically modulates brain functions related to both cognition and mood, thus it is plausible to hypothesize a synergistic effect of estrogen and serotonin on cognitive functioning, emotion processing, and affective regulation (Bethea et al., 2009). Indeed, selective serotonin re-uptake inhibitors are valid alternatives to estradiol for treatment of vasomotor symptoms, i.e., hot flashes, and depressive symptoms (Al-Safi and Santoro, 2014; Joffe et al., 2014). Future studies, ideally translational, must elucidate how the serotonin system integrates sex-steroid hormone information. In particular, the relative contributions from increases and decreases in sex-steroid levels, pre- and postsynaptic receptor involvement, and the timing of the responses, are warranted to advance our understanding of how changes in sex-hormone milieu may trigger cognitive dysfunction, depressive symptoms and mental disorders.

Dopamine. Estrogens, alone and in combination with progesterone, are likely to affect the dopaminergic system too as findings in non-human primate suggest an effect, although scattered and less prominent, of estrogen on the dopaminergic system (Voytko et al., 2009). To date one sole neuroimaging study has investigated the dopaminergic system in thirteen healthy postmenopausal women, reporting that dopamine transporter (DAT) availability in women was increased in the left anterior putamen after 4 weeks of estrogen-only treatment, and in the anterior putamen after 2 weeks of combined estrogen-progestagen treatment 
(Gardiner et al., 2004). Beside this study, long-term estrogen therapy has been reported to enhance dopaminergic responsivity to apomorphine in postmenopausal women (Craig et al., 2004), but further studies are needed.

\section{Other neurochemical markers}

MRS studies, through the detection of several metabolites (e.g., choline and $\mathrm{N}$-acetyl aspartate), provide proxy measures of neural integrity of the brain, neuronal/glial membrane turnover and function in menopause (Table 4). Never-treated postmenopausal women were shown to have higher Choline (Cho)-containing compounds in the parietal lobe and hippocampus, previously identified as regions-of-interest, compared to women on HRT, and long-term visual memory was negatively correlated with Cho in the hippocampus (Robertson et al., 2001). Young women after 8 weeks of induced ovarian suppression with a $\mathrm{GnRH}$ agonist had higher Cho, and Cho to creatine $(\mathrm{Cr})$ ratio, in the left dorsolateral prefrontal cortex (dlPFC), and borderline significant in the left hippocampus (Table 3) (Craig et al., 2007a). The Cho MRS peak mainly reflects the total amount of free acetylcholine, glycerophosphocholine, phosphocholine, and phosphoethanolamine; and Cho is a rate-limiting precursor in the synthesis of acetylcholine and a precursor of cell membrane phospholipids. These water soluble choline-containing compounds are proxy indicators of neuronal/glial cellular membrane turnover, and Cho levels are related to cognitive functioning and Alzheimer's disease (Chopra et al., 2011; Tayebati and Amenta, 2013). Increased Cho concentration may be due to loss of cholinergic neurons and/or increase in membrane phosphatidylcholine catabolism of neuronal cells to provide free Cho for the subsequent deficiency in acetylcholine production. In turn, membrane hypercatabolism may affect neuronal connectivity and signal transduction, causing impaired membrane processing (Chopra et al., 2011; Tayebati and Amenta, 2013).

Additionally, an increased N-acetyl aspartate (NAA) to total $\mathrm{Cr}(\mathrm{tCr})$ ratio in the hippocampus has been observed in postmenopausal women treated with low-dose HRT for more than 4 years compared to never-users, however, only among carriers of the dementia-related risk $\varepsilon 4$ allele of the apolipoprotein E (ApoE) gene (Table 4) (Yue et al., 2007). NAA is a neuronal marker reflecting neuronal density/function and/or mitochondrial metabolism; while tCR is mainly composed of phosphocreatine (PCr) and creatine (Cr), which are associated with high-energy phosphate metabolism, and constitute a marker for phosphate metabolism. At normal conditions tCr concentration $(\mathrm{Cr}+\mathrm{PCr})$ in the brain is very stable, which is why it can be used to normalize indexes, such as NAA/tCR. A decrease of NAA indicates damage or reduction of neurons, whereas an increase of NAA implies enhancement of the neuron metabolism thus suggesting a positive effect of HRT on neuronal function and metabolism. Nonetheless, gene-by-hormonal interactions have rarely been studied in relation to mental health in menopause. In this case, genetic risk conferred by the $\varepsilon 4$ allele of the ApoE gene (Yue et al., 2007), which has a dose-related effect on risk and onset age of $\mathrm{AD}$, seems to interact with HRT, and call for independent replication in larger samples. Genetic markers associated with neurodegenerative disorders might have interactive or addictive effects on hormonal shifts effects.

All together these neurochemical changes provide initial evidence of a beneficial effect of HRT on neuronal markers (Table 4). No significant effect of HRT on the concentration of other neurometabolites (e.g., myo-inositol, glutamate and glutamine) quantified with MRS have so far been reported (Craig et al., 2007a; Yue et al., 2007). Myo-inositol (ml) is a putative glial marker which affects neuronal signal transduction and cellular osmolarity, and increased $\mathrm{mI}$ has been found in neurodegenerative diseases; while a decrease of the sum of glutamate plus glutamine ( $\mathrm{glx}$ ) has been related to loss of glutamatergic neurons, reduced synthesis or increased demand of glutamate as an amino acid.

\section{BRAIN METABOLISM, RESTING STATE REGIONAL BLOOD FLOW AND FUNCTIONAL CONNECTIVITY}

Moreover, positron and single-photon computed emission tomography studies of resting state brain activity indicated a stimulating, or preserving, function of hormonal treatment for the cerebral blood flow and connectivity (Table 5), however, regions differing in cerebral glucose metabolism overlapped poorly between studies (Ohkura et al., 1995; Eberling et al., 2000; Maki and Resnick, 2000; Rasgon et al., 2001, 2005, 2014; Slopien et al., 2003; Kenna et al., 2009). Nevertheless, it remains unclear whether greater regional cerebral blood flow (rCBF) indicates better performance. PET studies assessing the rCBF employ rCBF as a marker of local neuronal activity; however questions remain about the source and meaning of the rCBF, as other mechanisms, such as changes in cerebrovascular response (vascular tone) must also be considered. SPECT also measures $\mathrm{rCBF}$, and is susceptible to hemodynamic changes, since intra-cerebral vessels are responsible for the $\mathrm{rCBF}$ and blood-brain barrier permeability; thus increased blood flow may be attributed to effects of estrogen on the cerebrovasculature (Ohkura et al., 1995; Eberling et al., 2000; Maki and Resnick, 2000; Rasgon et al., 2001, 2005, 2014; Slopien et al., 2003; Kenna et al., 2009). Finally, two recent studies of women at high risk for Alzheimer's disease provided evidence of differential changes in brain metabolism depending on estrogen formulation and/or estrogen-progestagen HRT (Silverman et al., 2011; Rasgon et al., 2014).

Nonetheless, HRT related brain activity and connectivity responses are not well elucidated (Table 5). In particular, so far no studies of resting state MRI have been published. However, lower mPFC-hippocampal connectivity at rest has been found in healthy postmenopausal women at risk for dementia who use HRT, in the presence of high plasma insulin levels (Kenna et al., 2013). Thus, studies of reproductive aging and HRT, and their relation with brain imaging of functional connectivity are needed.

\section{EMOTION PROCESSING}

The peri menopause is often accompanied by symptoms of depression and anxiety (Al-Safi and Santoro, 2014), and studies of rodents and non-human primates have attempted to investigate the neurobiology underlying postmenopausal-like affective processing (Shively and Bethea, 2004; Mueller et al., 2014). For instance, ovariectomized female rodents displayed less anxiety-like behavior when receiving estradiol replacement 


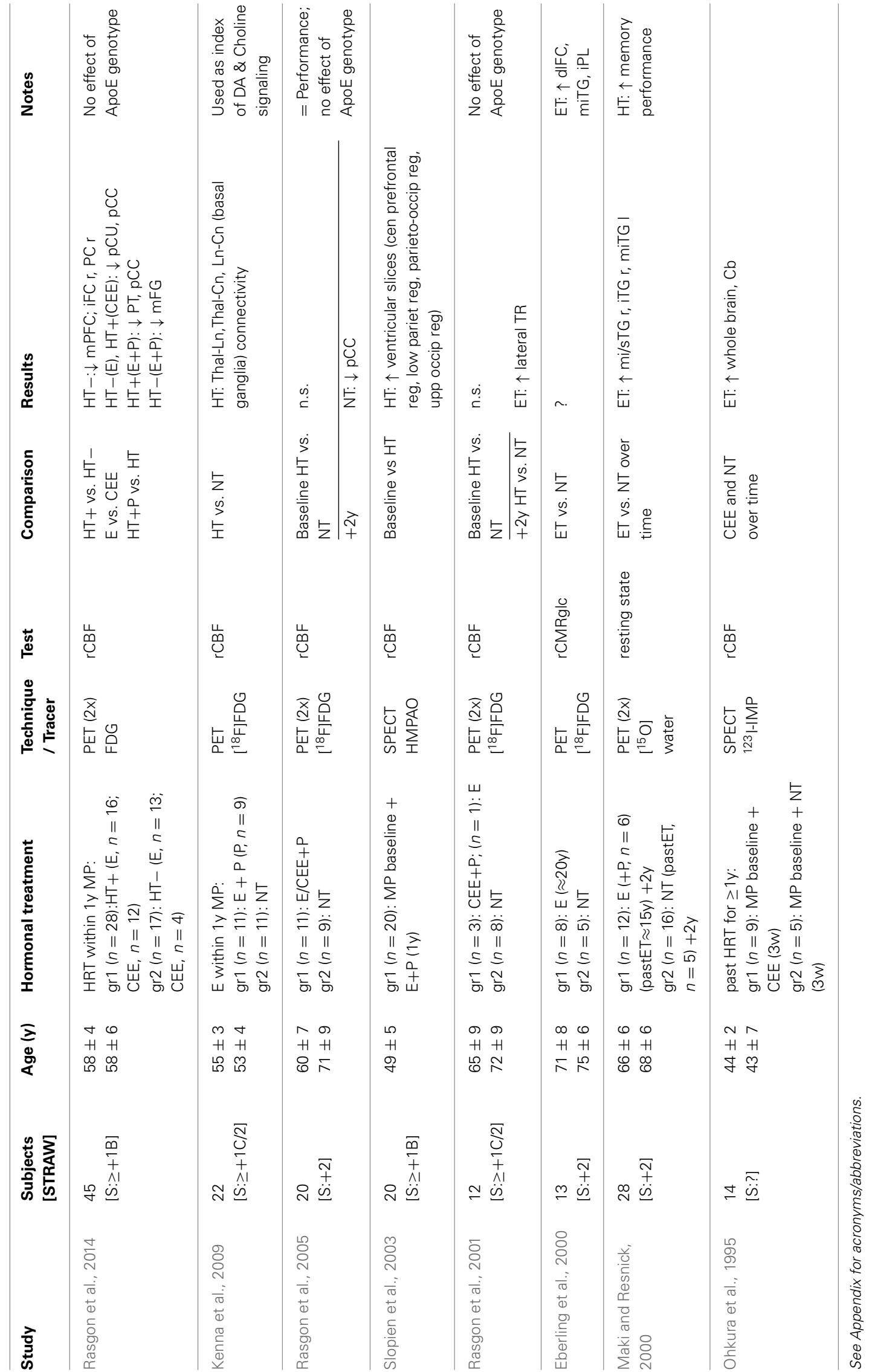




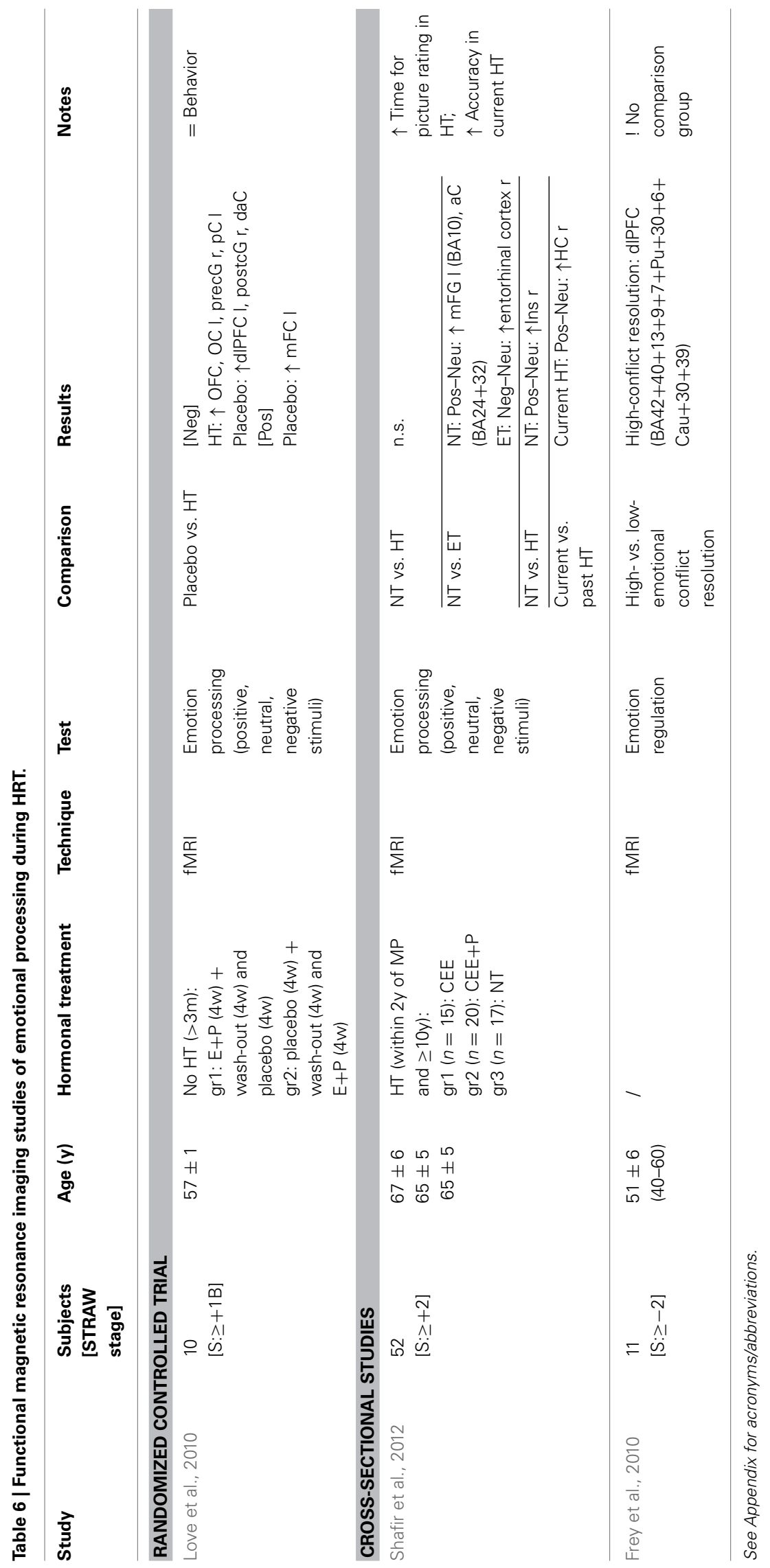


(Mueller et al., 2014). In humans, increased stress-triggered negative mood after a three-month estrogen administration was noted in healthy postmenopausal women (Newhouse et al., 2008), and in older women (Dumas et al., 2012a). However, HRT has been associated with decreased depressive symptoms in menopausal women (Zweifel and O'Brien, 1997), though depending on psychiatry history, age and study design; while other studies, such as the Women's Health Initiative study, provided conflicting evidence (Henderson and Greicius, 2010). Moreover, free estradiol levels were positively correlated with mood in a recent large study of healthy women during early postmenopause (Henderson et al., 2013), but again HRT, in particular current use, was associated with symptoms of depression and anxiety in two large cohorts of peri-menopausal women (Toffol et al., 2013), however estradiol is generally recognized to have positive effects on mood (Soares, 2013).

Neuroimaging studies of emotion processing in menopausal women are essentially lacking, and findings are thus far inconclusive (Table 6). A randomized placebo-controlled cross-over study including ten postmenopausal women portrayed an increased activation, though in different regions, during negative emotional stimuli processing, in both the placebo and estrogen-progestagen treated groups, and higher activation of the left medial frontal cortex during positive stimuli processing in the placebo group (Love et al., 2010). Later, a larger cross-sectional study of longterm HRT users also showed puzzling activation in estrogen treated women and non-users, and in current vs. past HRT users (Shafir et al., 2012). While Love et al. found no effect on performance of the task (Love et al., 2010), Shafir et al. found a slower response time in HRT users, but higher accuracy in picture rating among current users compared to past users (Shafir et al., 2012). In addition, greater regional activity in the dorsal lateral prefrontal cortex during high conflict resolution was found in one study investigating emotion regulation in eleven peri- and postmenopausal women (Frey et al., 2010).

Monoaminergic projections throughout the prefrontal and parietal cortices are likely mediating the effect of estrogen and progestagens on emotion and mood. Cortical and limbic structures are key regulators in emotion processing; principally the dorsolateral prefrontal cortex, playing a role in the suppression of emotion, was less activated during negative emotional stimuli in estrogen-progestagen treatment compared to placebo (Love et al., 2010), and the amygdala, a key region in emotional learning, had diminished emotion-induced activation after estrogen-only treatment in the presence of dampened serotonergic function (Epperson et al., 2012).

Interestingly, in relation to the "critical window" hypothesis, are the results of a functional magnetic resonance imaging study of older women, above the age of 65 years, comparing current long-term HRT users vs. past short-term users, and fundamentally indicating no difference in emotion-induced brain activity (Pruis et al., 2009). To sum up, the precise alterations in neural activity underlying the effects of HRT on mood in menopausal women remain to be understood, since a quarter of heterogeneous neuroimaging studies is not sufficient neither to tackle the question nor to draw conclusions.

\section{TESTOSTERONE TREATMENT}

Testosterone treatment in postmenopausal women has been investigated by only one study. An fMRI study of nine postmenopausal women indicated a decreased activation of frontal and lingual gyri during verbal fluency, and of the parietal lobe and precuneus during mental rotation, after 6 months of transdermal testosterone treatment (Davis et al., 2013). Higher endogenous testosterone has been associated with superior performance in verbal fluency, and spatial and mathematical abilities; thus these preliminary results might indicate a more efficient brain functioning in response to cognitive tasks.

Testosterone levels are about 65\% lower during menopause, and though ovarian production of testosterone continues after natural menopause, very low levels are gradually reached. Testosterone treatment is generally used for menopausal women with female sexual dysfunction, i.e., diminished sexual interest. Thus, knowledge of effect of testosterone replacement therapy in the brain should also be achieved, although it also remains to be established if putative effects are directly attributable to testosterone or rather due its conversion to estradiol, as has been showed convincingly for e.g., the $5-\mathrm{HT}_{2 \mathrm{~A}}$ receptor responses to HRT (Sumner and Fink, 1998).

\section{DISCUSSION}

Menopause is the most influential biological and health-related event for most middle-aged women. During the perimenopause (Harlow et al., 2012), which can last several years, the level of estrogen fluctuates substantially but gradually declines. The lowered estrogen levels are often accompanied by sometimes debilitating vasomotor symptoms (Harlow et al., 2012; Al-Safi and Santoro, 2014). The decision to use HRT or not represents a major concern for afflicted women and their clinicians. Effects of the menstrual cycle and pharmacological contraceptive treatment on the central nervous system, inferred from behavioral and neurophysiological activity changes in response to cognitive and emotional stimuli, indicate a role of estrogen and progesterone on brain function in healthy fertile women (Mueller et al., 2014; Toffoletto et al., 2014). Alike, menopausal hormone changes are likely to modulate neuronal activity and contribute to agerelated memory loss as well as the development of disorders such as dementia or major depression (Tables 1-6).

It is tempting to conclude that the present findings reflect true alterations in neural activity in the face of a hormonal perturbation (Tables 1-6). However, the interpretation of the results presented in this review remains a matter of debate, since less activation during task performance can be interpreted either as a more efficient use of neuronal resources or as an impaired state in which adequate activation of resources cannot be executed. Vice versa, higher activation can be interpreted as beneficial, or imply a compensatory response, or a less efficient use of resources (Henderson and Greicius, 2010). Interestingly, most of the effects were observed after a relatively brief time of HRT use. Thus, the optimal duration, or dose of HRT, or timing of treatment start, necessary to maintain a premenopausal cerebral state or to trigger neuroplasticity in mature women, is unknown.

Peri- and postmenopause are marked not only by vasomotor symptoms, but also by cognitive and emotional complaints that 
affect quality of life and overall functioning; however the degree to which the decline in estrogen and/or progesterone production is responsible is not yet clear. Increasing evidence from observational and HRT studies of postmenopausal women supports the influence of ovarian hormones on cognition and mood both at the behavioral and neural level, although it remains ambiguous whether this influence is positive or harmful (Henderson and Greicius, 2010). In the reviewed studies, estrogen altered the activation of brain structures underlying memory performance, particularly the fronto-cingulate region; however there appears to be a puzzling dissociation between neuropsychological performance and neural activity, since many studies that found a hormonaldependent effect in neuroimaging data did not observe neuropsychological alterations across hormonal conditions (Tables 1-3). Also, cerebral activity changes are task-dependent, as shown by experimental models (Sherwin and Henry, 2008; Gibbs, 2010), and may as well be biased by differences in education and health of the women. Longitudinal observations are hence indispensable to identify if, and at which critical age, the metabolic decline may become appreciable (Henderson and Greicius, 2010). Thus, abnormal activation when associated with normal task performance may reflect compensatory cerebral metabolic activity in response to a subtle/subclinical loss of cognitive capacity, and precede cognitive impairment in individuals at increased risk for neurodegenerative and psychiatric disorders. However, an alternative explanation to group differences in activation patterns during memory processes may be that postmenopausal women activate a distinct cognitive network. Overall, it seems plausible to conclude that estrogen, alone or in combination with progestagens, positively affects brain activation during memory processing in postmenopausal women (Tables 1, 2), likely via interactions with basal forebrain cholinergic projections (Gibbs, 2010). This suggestion is also in line with findings of preserved visual memory in ovariectomized monkeys treated with estrogen, alone or in combination with progesterone, compared to placebotreated ovariectomized monkeys (Voytko et al., 2009). In contrast, results regarding cerebral functional responsiveness to emotional stimulation are lacking and far from being consistent (Table 6).

Furthermore, studies of neurochemical pathways have pinpointed the cholinergic, serotonergic, and dopaminergic systems as biological mediators of estrogen influences on the brain (Table 4). Cholinergic and monoaminergic wide-spread projections to prefrontal cortical regions interactively mediate several functions ranging from working memory to emotion processing. For instance, quantitative and qualitative differences in density of axons immunoreactive to ChAT, dopamine $ß$-hydroxylase, tyrosine hydroxylase and serotonin in the dorsal medial prefrontal cortex was found in ovariectomized monkeys compared to control animals, and following 1 month treatment with estrogen-only or estrogen-progesterone (Kritzer and Kohama, 1998, 1999). The interplay between these neurotransmitter systems is of relevance for schizophrenia and depression, two mental disorders characterized by sex differences in their occurrence, and their interaction with hormonal changes is likely to impact treatment response.

More, knowing that cerebral blood flow decreases with age, positron, and single-photon computed emission tomography studies suggested a preservative/stimulating function of estrogen for the cerebral blood flow (Table 5). In view of these findings (Tables 1-5), and of studies of monkeys (Voytko et al., 2009), a putative neuroprotective role of estrogen in neuronal integrity maintenance and cognitive function preservation against regional cerebral metabolic decline could thus be anticipated/predicted, also considering meta-analytical findings reporting an effect of about one-third reduction in the risk of Alzheimer's disease among HRT users (Yaffe et al., 1998; Hogervorst et al., 2000; LeBlanc et al., 2001; Nelson et al., 2002). However, as highlighted by the Women's Health Initiative project, timing is likely to be critical for positive HRT effects on cognition (Henderson and Greicius, 2010).

Of special interest in relation to neurogenesis and synaptic plasticity is the hippocampus, a crucial region in memory and learning (Gibbs, 2010). Preclinical research has highlighted several effects of estrogen on structure and function of the hippocampus in animal experiments, also via effects on cholinergic projections from the forebrain, ranging from neurotrophic to neuroplastic to neurobehavioral effects (Voytko et al., 2009; Wnuk et al., 2012; Daniel, 2013). The hippocampus is atrophied and functionally impaired in Alzheimer's disease and in the presence of a history of repeated depressive episodes, neurobiological features which are linked to cognitive function. Larger hippocampal volume in HRT users has been indicated by magnetic resonance imaging studies, with the first evidence reported by Eberling et al. (2003). Several experimental and clinical studies have in fact provided evidence of a positive modulatory effect of estrogen use on hippocampal anatomy, though aversive or absent effects have also been reported (Erickson et al., 2005, 2010; Boccardi et al., 2006; Lord et al., 2008; Espeland et al., 2009; Wnuk et al., 2012). Discordance of the findings and lack of longitudinal randomized controlled trials leaves room for equivocal conclusions on the effects of HRT on hippocampus morphology. However, several neuroimaging studies indicated an enhancing effect of HRT on hippocampus function (Maki and Resnick, 2000; Robertson et al., 2001; Gleason et al., 2006; Norbury et al., 2007; Berent-Spillson et al., 2010; Maki et al., 2011; Smith et al., 2011; Shafir et al., 2012), suggesting potential positive estrogenmediated effects on neuronal survival and plasticity through the cholinergic system (Daniel, 2013). Thus hippocampal, together with prefrontal cortical, function is a strong candidate substrate mediating the hormonal effects on cognition.

Estrogens interact with neuronal networks at many levels and affect brain development and aging (Sherwin and Henry, 2008). The modulation by estrogen may therefore account for hormonal regulation of cognition and mood, as for instance women have increased risk for developing Alzheimer's dementia and major depression compared to men, but the pathophysiological mechanisms behind these differences are unknown (Henderson and Greicius, 2010). Non-invasive measurement of brain function through neuroimaging techniques is advantageous compared to traditional behavioral measures. The BOLD signal and the $\mathrm{rCBF}$ are proxy outcomes, endpoints which can be objectively measured and are potentially related to a clinical phenotype, such as working memory (Henderson and Greicius, 2010). Biological relevance could thus be inferred by the effect of HRT on neuronal activity; consequently the question whether certain intermediate 
phenotypes can be classified as endophenotypes (Lenzenweger, 2013) for neurodegenerative and psychiatric disorders occurring during menopause remain to be addressed. Neuroimaging genetics of the peri- and postmenopause and HRT use is required to provide knowledge about constitutional vulnerability to hormonal changes in relation to mental health (e.g., the first neuroimaging genetic study of premenstrual dysphoric disorder, Comasco et al., 2014), as well as molecular research will be essential to elucidate epi-genotype-mediated mechanisms. To date there is a lack of focus on genetic correlates of menopausal hormonal effects, with only four studies having considered the ApoE genotype (Rasgon et al., 2001, 2005; Robertson et al., 2001; Yue et al., 2007). For instance polymorphisms in the estrogen receptor alpha and beta genes (ESR1 and ESR2) have been associated with cognitive impairment in old women in two large longitudinal studies (Yaffe et al., 2002, 2009), but their potential intermediate neuronal correlates have not been investigated. Additionally, the modulatory association between the catecholamine degrading enzyme catechol-O-methyltransferase (COMT) and dorso and ventro lateral prefrontal cortex and supragenual anterior cingulate cortex activation during working memory has been demonstrated in schizophrenia (Rasetti and Weinberger, 2011), but remains to be explored in relation to menopausal cognitive decline.

Future studies will thus need to investigate whether putative intermediate phenotypes are involved in the causal pathway between genes and psychopathology, besides having a mere associative or consequential relationship with the illness, as well as the heritability of the endophenotype(s) (Lenzenweger, 2013). By means of such approach, differences between statistical vs. biological significance can be further discerned.

Widespread classical nuclear (i.e., estrogen receptor $\alpha$ and $\beta$, progesterone receptor $\mathrm{A}$ and $\mathrm{B}$ ), and non-classical membraneassociated (e.g., G protein-coupled estrogen receptors and the progesterone receptor membrane component 1), receptors are targeted by estradiol and progesterone, thus mediating their effects on brain structure as well as cognitive-affective processing (Brinton et al., 2008; Wharton et al., 2012). Remarkably, estrogen replacement treatment has been the most studied (Tables 1-6), even though it is far less often used compared to combined estrogen-progestagen treatment. Estrogen-only treatment is prescribed only for hysterectomized women, as the progestagen addition is needed for protection against endometrial hyperplasia and cancer. Moreover, two recent studies of women at high risk for Alzheimer's disease provided evidence of differential changes in brain metabolism depending on estrogen formulation and/or estrogen-progestagen HRT (Silverman et al., 2011; Rasgon et al., 2014). Lately, a study found a positive correlation between serum progesterone, but not estrogen, levels and verbal memory and global cognition in healthy women during the early postmenopause (Henderson et al., 2013). Thus, potential cumulative neuroprotective or counteracting effects of progestagensvia its metabolites or indirectly via type-A $\gamma$-aminobutyric acid receptor signaling modulation-still need to be elucidated.

Importantly sampling differences between the studies also need to be considered since a gynecological clinic-based sample (e.g., women who underwent oophorectomy with or without hysterectomy, i.e., surgical menopause) is likely to differ from a sample of asymptomatic healthy menopausal women (Rocca et al., 2014). Furthermore, natural menopause is typified by a gradual decline of estradiol and androgen levels until circulating levels are exclusively maintained by peripheral conversion of adrenal steroids (Harlow et al., 2012; Al-Safi and Santoro, 2014). On the contrary, surgical menopause causes a drastic and complete cessation of both estradiol and testosterone secretion. Finally, efforts to stage reproductive aging according to standardized nomenclature and classifications, as the Stages of Reproductive Aging Workshop (STRAW) criteria, should be made to facilitate comparisons between studies (Harlow et al., 2012).

Hormonal supplementation in peri- and postmenopausal women remains a source of great health concern. The so-called "window of opportunity" or "critical period" hypothesis cannot be rejected based on the present results, but it is expectable that timing of HRT (i.e., age and proximity to menopause when HRT is initiated) will imply a different brain response, and that chronological and reproductive aging matter too (Henderson and Greicius, 2010; Daniel, 2013; Maki, 2013; Rocca et al., 2014). A critical threshold below which the function of neurobiological systems remains impaired by loss of ovarian function and cannot be triggered by exogenous hormonal supplementation is indeed plausible.

\section{CONCLUSIONS}

Questions to-be-answered:

I. What are the neurobiological mechanisms underlying menopause hormonal transition and HRT effects in the brain?

II. Are there synergistic or counteracting effects of estrogen together with progestagens and/or androgens?

III. Which dosage and combination of HRT should be prescribed?

IV. If and when should HRT be initialized and terminated to be most efficient in optimizing women's mental health?

Collectively, neuroimaging studies indicate altered brain activation patterns by estrogen-only or estrogen-progestagen treatment in therapeutic doses in postmenopausal women, corroborating preclinical findings of effects of estrogen on neural structure and function in mature animals. These results call for further well-powered randomized-controlled multi-modal neuroimaging studies, using a battery of standardized neuropsychological tests, as well as for complementary investigation on the correlated molecular mechanisms of reproductive aging and HRT in preclinical models.

\section{KEY CONCEPTS}

- Menopausal transition: period in a women's life lasting several years around the age of fifty where ovarian hormone levels, estrogens and androgens, fluctuate and decrease until menopause occurs with the termination of the menstrual cycle, and post-menopause is established; this physiological transitional hormonal change (peri-menopause), as well as surgically 
induced menopausal transition, are of relevance to the aging female brain.

- Hormonal replacement therapy (HRT): exogenous supplementation of estrogen and/or progesterone given during perimenopause to treat vasomotor symptoms. The potential protective and/or aversive effects, and the biological mechanism of action of HRT, as well as the effects of interrupting HRT, on cognitive and emotional functioning remain largely elusive.

- Window of opportunity: crucial period of time spanning from peri- to post-menopause during which HRT could be used with beneficial effects on women's physical and mental health.

- GnRHa hormone manipulation: treatment with a gonadotropin releasing hormone agonist that initiates a biphasic response, which initially stimulates ovarian sexsteroid hormone production and subsequently induces a pharmacological pseudo-menopausal state, which is established by the second to fourth week of administration, with a complete cessation of both estradiol and testosterone secretion. It provides a model of early menopause and menopausal transition.

\section{AUTHOR CONTRIBUTIONS}

Erika Comasco, Inger Sundström-Poromaa, and Vibe G. Frokjaer: study conception; literature acquisition; data interpretation; drafting the work; revising the work critically for important intellectual content; final approval of the version to be published; and agreement to be accountable for all aspects of the work in ensuring that questions related to the accuracy or integrity of any part of the work are appropriately investigated and resolved.

\section{ACKNOWLEDGMENTS}

The study was partially supported by funds from the Swedish Council for Working Life and Social Research to Erika Comasco (FAS: 2011-0627) and Inger Sundström-Poromaa (FAS: 20071955), the Swedish Society of Medicine (SLS-331991) to Erika Comasco, and the Swedish Research Council to Inger SundströmPoromaa (VR: 521-2010-3293); and from The Danish Council for Independent Research, The Lundbeck Foundation (Cimbi), and The Capital Region of Denmark, Foundation for Health Research to Vibe G. Frokjaer.

\section{REFERENCES}

Al-Safi, Z. A., and Santoro, N. (2014). Menopausal hormone therapy and menopausal symptoms. Fertil. Steril. 101, 905-915. doi: 10.1016/j.fertnstert. 2014.02.032

Berent-Spillson, A., Persad, C. C., Love, T., Sowers, M., Randolph, J. F., Zubieta, J. K., et al. (2012). Hormonal environment affects cognition independent of age during the menopause transition. J. Clin. Endocrinol. Metab. 97, 2012-1365. doi: 10.1210/jc.2012-1365

Berent-Spillson, A., Persad, C. C., Love, T., Tkaczyk, A., Wang, H., Reame, N. K., et al. (2010). Early menopausal hormone use influences brain regions used for visual working memory. Menopause 17, 692-699. doi: 10.1097/gme.0b013e3181cc49e9

Berman, K. F., Schmidt, P. J., Rubinow, D. R., Danaceau, M. A., Van Horn, J. D., Esposito, G., et al. (1997). Modulation of cognition-specific cortical activity by gonadal steroids: a positron-emission tomography study in women. Proc. Natl. Acad. Sci. U.S.A. 94, 8836-8841. doi: 10.1073/pnas.94.16.8836

Bethea, C. L., Reddy, A. P., Tokuyama, Y., Henderson, J. A., and Lima, F. B. (2009). Protective actions of ovarian hormones in the serotonin system of macaques. Front. Neuroendocrinol. 30, 212-238. doi: 10.1016/j.yfrne.2009. 04.003

Biegon, A., Reches, A., Snyder, L., and McEwen, B. S. (1983). Serotonergic and noradrenergic receptors in the rat brain: modulation by chronic exposure to ovarian hormones. Life Sci. 32, 2015-2021. doi: 10.1016/0024-3205(83)90053-X

Birzniece, V., Johansson, I. M., Wang, M. D., Backstrom, T., and Olsson, T. (2002). Ovarian hormone effects on 5-hydroxytryptamine(2A) and 5hydroxytryptamine(2C) receptor mRNA expression in the ventral hippocampus and frontal cortex of female rats. Neurosci. Lett. 319, 157-161. doi: 10.1016/S0304-3940(01)02570-8

Boccardi, M., Ghidoni, R., Govoni, S., Testa, C., Benussi, L., Bonetti, M., et al. (2006). Effects of hormone therapy on brain morphology of healthy postmenopausal women: a Voxel-based morphometry study. Menopause 13, 584-591. doi: 10.1097/01.gme.0000196811.88505.10

Brinton, R. D., Thompson, R. F., Foy, M. R., Baudry, M., Wang, J., Finch, C. E., et al. (2008). Progesterone receptors: form and function in brain. Front. Neuroendocrinol. 29, 313-339. doi: 10.1016/j.yfrne.2008.02.001

Chopra, K., Misra, S., and Kuhad, A. (2011). Neurobiological aspects of Alzheimer's disease. Expert Opin. Ther. Targets 15, 535-555. doi: 10.1517/14728222.2011. 557363

Comasco, E., Hahn, A., Ganger, S., Gingnell, M., Bannbers, E., Oreland, L., et al. (2014). Emotional fronto-cingulate cortex activation and brain derived neurotrophic factor polymorphism in premenstrual dysphoric disorder. Hum. Brain Mapp. 35, 4450-4458. doi: 10.1002/hbm.22486

Compton, J., Travis, M. J., Norbury, R., Erlandsson, K., van Amelsvoort, T., Daly, E., et al. (2008). Long-term estrogen therapy and 5-HT(2A) receptor binding in postmenopausal women; a single photon emission tomography (SPET) study. Horm. Behav. 53, 61-68. doi: 10.1016/j.yhbeh.2007.08.014

Craig, M. C., Brammer, M., Maki, P. M., Fletcher, P. C., Daly, E. M., Rymer, J., et al. (2010). The interactive effect of acute ovarian suppression and the cholinergic system on visuospatial working memory in young women. Psychoneuroendocrinology 35, 987-1000. doi: 10.1016/j.psyneuen.2009.12.012

Craig, M. C., Cutter, W. J., Wickham, H., van Amelsvoort, T. A., Rymer, J., Whitehead, M., et al. (2004). Effect of long-term estrogen therapy on dopaminergic responsivity in post-menopausal women-a preliminary study. Psychoneuroendocrinology 29, 1309-1316. doi: 10.1016/j.psyneuen.2004.03.008

Craig, M. C., Daly, E. M., O'Gorman, R., Rymer, J., Lythgoe, D., Ng, G., et al. (2007a). Effects of acute ovarian hormone suppression on the human brain: an in vivo $1 \mathrm{H}$ MRS study. Psychoneuroendocrinology 32, 1128-1132. doi: 10.1016/j.psyneuen.2007.06.004

Craig, M. C., Fletcher, P. C., Daly, E. M., Picchioni, M. M., Brammer, M., Giampietro, V., et al. (2008a). A study of visuospatial working memory pre- and post-Gonadotropin Hormone Releasing Hormone agonists (GnRHa) in young women. Horm. Behav. 54, 47-59. doi: 10.1016/j.yhbeh.2008.01.012

Craig, M. C., Fletcher, P. C., Daly, E. M., Rymer, J., Brammer, M., Giampietro, V., et al. (2008b). Reversibility of the effects of acute ovarian hormone suppression on verbal memory and prefrontal function in pre-menopausal women. Psychoneuroendocrinology 33, 1426-1431. doi: 10.1016/j.psyneuen.2008.08.006

Craig, M. C., Fletcher, P. C., Daly, E. M., Rymer, J., Brammer, M., Giampietro, V., et al. (2009). The interactive effect of the cholinergic system and acute ovarian suppression on the brain: an fMRI study. Horm. Behav. 55, 41-49. doi: 10.1016/j.yhbeh.2008.08.008

Craig, M. C., Fletcher, P. C., Daly, E. M., Rymer, J., Cutter, W. J., Brammer, M., et al. (2007b). Gonadotropin hormone releasing hormone agonists alter prefrontal function during verbal encoding in young women. Psychoneuroendocrinology 32, 1116-1127. doi: 10.1016/j.psyneuen.2007.09.009

Cyr, M., Bosse, R., and Di Paolo, T. (1998). Gonadal hormones modulate 5-hydroxytryptamine2A receptors: emphasis on the rat frontal cortex. Neuroscience 83, 829-836. doi: 10.1016/S0306-4522(97)00445-4

Daniel, J. M. (2013). Estrogens, estrogen receptors, and female cognitive aging: the impact of timing. Horm. Behav. 63, 231-237. doi: 10.1016/j.yhbeh.2012. 05.003

Davis, S. R., Davison, S. L., Gavrilescu, M., Searle, K., Gogos, A., Rossell, S. L., et al. (2013). Effects of testosterone on visuospatial function and verbal fluency in postmenopausal women: results from a functional magnetic resonance imaging pilot study. Menopause 21, 410-414. doi: 10.1097/GME.0b013e3182a065ed

Davison, S. L., Bell, R. J., Robinson, P. J., Jane, F., Leech, J., Maruff, P., et al. (2013). Continuous-combined oral estradiol/drospirenone has no detrimental effect on cognitive performance and improves estrogen deficiency symptoms in early 
postmenopausal women: a randomized placebo-controlled trial. Menopause 20, 1020-1026. doi: 10.1097/GME.0b013e318287474f

Dumas, J. A., Albert, K. M., Naylor, M. R., Sites, C. K., Benkelfat, C., and Newhouse, P. A. (2012a). The effects of age and estrogen on stress responsivity in older women. Am. J. Geriatr. Psychiatry 20, 734-743. doi: 10.1097/JGP.0b013e31825c0a14

Dumas, J. A., Kutz, A. M., Naylor, M. R., Johnson, J. V., and Newhouse, P. A. (2010). Increased memory load-related frontal activation after estradiol treatment in postmenopausal women. Horm. Behav. 58, 929-935. doi: 10.1016/j.yhbeh.2010.09.003

Dumas, J. A., Kutz, A. M., Naylor, M. R., Johnson, J. V., and Newhouse, P. A. (2012b). Estradiol treatment altered anticholinergic-related brain activation during working memory in postmenopausal women. Neuroimage 60 , 1394-1403. doi: 10.1016/j.neuroimage.2012.01.043

Dumas, J., Hancur-Bucci, C., Naylor, M., Sites, C., and Newhouse, P. (2006) Estrogen treatment effects on anticholinergic-induced cognitive dysfunction in normal postmenopausal women. Neuropsychopharmacology 31, 2065-2078. doi: 10.1038/sj.npp.1301042

Dumas, J., Hancur-Bucci, C., Naylor, M., Sites, C., and Newhouse, P. (2008). Estradiol interacts with the cholinergic system to affect verbal memory in postmenopausal women: evidence for the critical period hypothesis. Horm. Behav. 53, 159-169. doi: 10.1016/j.yhbeh.2007.09.011

Eberling, J. L., Reed, B. R., Coleman, J. E., and Jagust, W. J. (2000). Effect of estrogen on cerebral glucose metabolism in postmenopausal women. Neurology 55 875-877. doi: 10.1212/WNL.55.6.875

Eberling, J. L., Wu, C., Haan, M. N., Mungas, D., Buonocore, M., and Jagust, W. J. (2003). Preliminary evidence that estrogen protects against age-related hippocampal atrophy. Neurobiol. Aging 24, 725-732. doi: 10.1016/S01974580(02)00056-8

Epperson, C. N., Amin, Z., Ruparel, K., Gur, R., and Loughead, J. (2012). Interactive effects of estrogen and serotonin on brain activation during working memory and affective processing in menopausal women. Psychoneuroendocrinology 37 372-382. doi: 10.1016/j.psyneuen.2011.07.007

Epperson, C. N., Sammel, M. D., and Freeman, E. W. (2013). Menopause effects on verbal memory: findings from a longitudinal community cohort. J. Clin. Endocrinol. Metab. 98, 3829-3838. doi: 10.1210/jc.2013-1808

Erickson, K. I., Colcombe, S. J., Raz, N., Korol, D. L., Scalf, P., Webb, A., et al. (2005). Selective sparing of brain tissue in postmenopausal women receiving hormone replacement therapy. Neurobiol. Aging 26, 1205-1213. doi: 10.1016/i.neurobiolaging.2004.11.009

Erickson, K. I., Voss, M. W., Prakash, R. S., Chaddock, L., and Kramer, A. F. (2010). A cross-sectional study of hormone treatment and hippocampal volume in postmenopausal women: evidence for a limited window of opportunity. Neuropsychology 24, 68-76. doi: 10.1037/a0017292

Espeland, M. A., Tindle, H. A., Bushnell, C. A., Jaramillo, S. A., Kuller, L. H., Margolis, K. L., et al. (2009). Brain volumes, cognitive impairment, and conjugated equine estrogens. J. Gerontol. A Biol. Sci. Med. Sci. 64, 1243-1250. doi: 10.1093/gerona/glp128

Freeman, E. W., Sammel, M. D., Boorman, D. W., and Zhang, R. (2014). Longitudinal pattern of depressive symptoms around natural menopause. JAMA Psychiatry 71, 36-43. doi: 10.1001/jamapsychiatry.2013. 2819

Freeman, E. W., Sammel, M. D., Lin, H., and Nelson, D. B. (2006). Associations of hormones and menopausal status with depressed mood in women with no history of depression. Arch. Gen. Psychiatry 63, 375-382. doi: 10.1001/archpsyc.63.4.375

Frey, B. N., Hall, G. B., Attard, S., Yucel, K., Skelin, I., Steiner, M., et al. (2010). Shift in the brain network of emotional regulation in midlife women: is the menopausal transition the turning point? Menopause 17, 840-845. doi: 10.1097/gme.0b013e3181df840f

Frokjaer, V. G., Erritzoe, D., Juul, A., Nielsen, F. A., Holst, K., Svarer, C., et al. (2010). Endogenous plasma estradiol in healthy men is positively correlated with cerebral cortical serotonin $2 \mathrm{~A}$ receptor binding. Psychoneuroendocrinology 35, 1311-1320. doi: 10.1016/j.psyneuen.2010.03.002

Gardiner, S. A., Morrison, M. F., Mozley, P. D., Mozley, L. H., Brensinger, C., Bilker, W., et al. (2004). Pilot study on the effect of estrogen replacement therapy on brain dopamine transporter availability in healthy, postmenopausal women. Am. J. Geriatr. Psychiatry 12, 621-630. doi: 10.1176/appi.ajgp. 12.6 .621
Gibbs, R. B. (2000). Effects of gonadal hormone replacement on measures of basal forebrain cholinergic function. Neuroscience 101, 931-938. doi: 10.1016/S03064522(00)00433-4

Gibbs, R. B. (2010). Estrogen therapy and cognition: a review of the cholinergic hypothesis. Endocr. Rev. 31, 224-253. doi: 10.1210/er.2009-0036

Gleason, C. E., Schmitz, T. W., Hess, T., Koscik, R. L., Trivedi, M. A., Ries, M. L., et al. (2006). Hormone effects on fMRI and cognitive measures of encoding: importance of hormone preparation. Neurology 67, 2039-2041. doi: 10.1212/01.wnl.0000247277.81400.43

Grigorova, M., Sherwin, B. B., and Tulandi, T. (2006). Effects of treatment with leuprolide acetate depot on working memory and executive functions in young premenopausal women. Psychoneuroendocrinology 31, 935-947. doi: 10.1016/j.psyneuen.2006.05.004

Hafner, H. (2003). Gender differences in schizophrenia. Psychoneuroendocrinology 28(Suppl. 2), 17-54. doi: 10.1016/S0306-4530(02)00125-7

Hafner, H., Maurer, K., Loffler, W., and Riecher-Rossler, A. (1993). The influence of age and sex on the onset and early course of schizophrenia. Br. J. Psychiatry 162, 80-86. doi: 10.1192/bjp.162.1.80

Harlow, S. D., Gass, M., Hall, J. E., Lobo, R., Maki, P., Rebar, R. W., et al. (2012). Executive summary of the stages of reproductive aging workshop +10 : addressing the unfinished agenda of staging reproductive aging. Menopause 19, 387-395. doi: 10.1097/gme.0b013e31824d8f40

Haugbol, S., Pinborg, L. H., Arfan, H. M., Frokjaer, V. M., Madsen, J., Dyrby, T. B., et al. (2007). Reproducibility of 5-HT2A receptor measurements and sample size estimations with $[18 \mathrm{~F}]$ altanserin PET using a bolus/infusion approach. Eur. J. Nucl. Med. Mol. Imaging 34, 910-915. doi: 10.1007/s00259-006-0296-y

Henderson, J. A., and Bethea, C. L. (2008). Differential effects of ovarian steroids and raloxifene on serotonin $1 \mathrm{~A}$ and $2 \mathrm{C}$ receptor protein expression in macaques. Endocrine 33, 285-293. doi: 10.1007/s12020-008-9087-5

Henderson, V. W., and Greicius, M. D. (2010). Functional magnetic resonance imaging and estrogen effects on the brain: cautious interpretation of a BOLD finding. Menopause 17, 669-671. doi: 10.1097/gme.0b013e3181e3a50e

Henderson, V. W., St John, J. A., Hodis, H. N., McCleary, C. A., Stanczyk, F. Z., Karim, R., et al. (2013). Cognition, mood, and physiological concentrations of sex hormones in the early and late postmenopause. Proc. Natl. Acad. Sci. U.S.A. 110, 20290-20295. doi: 10.1073/pnas.1312353110

Hogervorst, E., Williams, J., Budge, M., Riedel, W., and Jolles, J. (2000). The nature of the effect of female gonadal hormone replacement therapy on cognitive function in post-menopausal women: a meta-analysis. Neuroscience 101, 485-512. doi: 10.1016/S0306-4522(00)00410-3

Joffe, H., Guthrie, K. A., LaCroix, A. Z., Reed, S. D., Ensrud, K. E., Manson, J. E., et al. (2014). Low-dose estradiol and the serotonin-norepinephrine reuptake inhibitor venlafaxine for vasomotor symptoms: a randomized clinical trial. JAMA Intern. Med. 174, 1058-1066. doi: 10.1001/jamainternmed.2014.1891

Joffe, H., Hall, J. E., Gruber, S., Sarmiento, I. A., Cohen, L. S., Yurgelun-Todd, D., et al. (2006). Estrogen therapy selectively enhances prefrontal cognitive processes: a randomized, double-blind, placebo-controlled study with functional magnetic resonance imaging in perimenopausal and recently postmenopausal women. Menopause 13, 411-422. doi: 10.1097/01.gme.0000189618.48774.7b

Kenna, H. A., Rasgon, N. L., Geist, C., Small, G., and Silverman, D. (2009). Thalamo-Basal Ganglia connectivity in postmenopausal women receiving estrogen therapy. Neurochem. Res. 34, 234-237. doi: 10.1007/s11064-008-9756-Z

Kenna, H., Hoeft, F., Kelley, R., Wroolie, T., DeMuth, B., Reiss, A., et al. (2013). Fasting plasma insulin and the default mode network in women at risk for Alzheimer's disease. Neurobiol. Aging 34, 641-649. doi: 10.1016/j.neurobiolaging.2012.06.006

Kranz, G. S., Rami-Mark, C., Kaufmann, U., Baldinger, P., Hahn, A., Hoflich, A., et al. (2014). Effects of hormone replacement therapy on cerebral serotonin-1A receptor binding in postmenopausal women examined with [carbonyl-(11)C]WAY-100635. Psychoneuroendocrinology 45, 1-10. doi: 10.1016/j.psyneuen.2014.03.004

Kritzer, M. F., and Kohama, S. G. (1998). Ovarian hormones influence the morphology, distribution, and density of tyrosine hydroxylase immunoreactive axons in the dorsolateral prefrontal cortex of adult rhesus monkeys. J. Comp. Neurol. 395, 1-17. doi: 10.1002/(SICI)1096-9861(19980525)395:1<1::AID$\mathrm{CNE} 1>3.0 . \mathrm{CO} ; 2-4$

Kritzer, M. F., and Kohama, S. G. (1999). Ovarian hormones differentially influence immunoreactivity for dopamine beta- hydroxylase, choline acetyltransferase, and serotonin in the dorsolateral prefrontal cortex of adult 
rhesus monkeys. J. Comp. Neurol. 409, 438-451. doi: 10.1002/(SICI)10969861(19990705)409:3<438::AID-CNE8>3.0.CO;2-5

Kugaya, A., Epperson, C. N., Zoghbi, S., van Dyck, C. H., Hou, Y., Fujita, M., et al. (2003). Increase in prefrontal cortex serotonin $2 \mathrm{~A}$ receptors following estrogen treatment in postmenopausal women. Am. J. Psychiatry 160, 1522-1524. doi: 10.1176/appi.ajp.160.8.1522

LeBlanc, E. S., Janowsky, J., Chan, B. K., and Nelson, H. D. (2001). Hormone replacement therapy and cognition: systematic review and meta-analysis. JAMA 285, 1489-1499. doi: 10.1001/jama.285.11.1489

Lenzenweger, M. F. (2013). Thinking clearly about the endophenotypeintermediate phenotype-biomarker distinctions in developmental psychopathology research. Dev. Psychopathol. 25, 1347-1357. doi: 10.1017/ S0954579413000655

Lord, C., Buss, C., Lupien, S. J., and Pruessner, J. C. (2008). Hippocampal volumes are larger in postmenopausal women using estrogen therapy compared to past users, never users and men: a possible window of opportunity effect. Neurobiol. Aging 29, 95-101. doi: 10.1016/j.neurobiolaging.2006.09.001

Love, T., Smith, Y. R., Persad, C. C., Tkaczyk, A., and Zubieta, J. K. (2010). Short-term hormone treatment modulates emotion response circuitry in postmenopausal women. Fertil. Steril. 93, 1929-1937. doi: 10.1016/j.fertnstert.2008.12.056

Lu, N. Z., and Bethea, C. L. (2002). Ovarian steroid regulation of 5-HT1A receptor binding and $\mathrm{G}$ protein activation in female monkeys. Neuropsychopharmacology 27, 12-24. doi: 10.1016/S0893-133X(01)00423-7

Maki, P. M. (2013). Critical window hypothesis of hormone therapy and cognition: a scientific update on clinical studies. Menopause 20, 695-709. doi: 10.1097/GME.0b013e3182960cf8

Maki, P. M., Dennerstein, L., Clark, M., Guthrie, J., LaMontagne, P., Fornelli, D., et al. (2011). Perimenopausal use of hormone therapy is associated with enhanced memory and hippocampal function later in life. Brain Res. 1379, 232-243. doi: 10.1016/j.brainres.2010.11.030

Maki, P. M., and Resnick, S. M. (2000). Longitudinal effects of estrogen replacement therapy on PET cerebral blood flow and cognition. Neurobiol. Aging 21, 373-383. doi: 10.1016/S0197-4580(00)00123-8

Marjoribanks, J., Farquhar, C., Roberts, H., and Lethaby, A. (2012). Long term hormone therapy for perimenopausal and postmenopausal women. Cochrane Database Syst. Rev. 7, CD004143. doi: 10.1002/14651858.CD004143. pub4

Meyer-Lindenberg, A., and Weinberger, D. R. (2006). Intermediate phenotypes and genetic mechanisms of psychiatric disorders. Nat. Rev. Neurosci. 7, 818-827. doi: 10.1038/nrn1993

Moses, E. L., Drevets, W. C., Smith, G., Mathis, C. A., Kalro, B. N., Butters, M. A., et al. (2000). Effects of estradiol and progesterone administration on human serotonin 2A receptor binding: a PET study. Biol. Psychiatry 48, 854-860. doi: 10.1016/S0006-3223(00)00967-7

Moses-Kolko, E. L., Berga, S. L., Greer, P. J., Smith, G., Cidis Meltzer, C., and Drevets, W. C. (2003). Widespread increases of cortical serotonin type $2 \mathrm{~A}$ receptor availability after hormone therapy in euthymic postmenopausal women. Fertil. Steril. 80, 554-559. doi: 10.1016/S0015-0282(03)00973-7

Mueller, S. C., Grissom, E. M., and Dohanich, G. P. (2014). Assessing gonadal hormone contributions to affective psychopathologies across humans and animal models. Psychoneuroendocrinology 46C, 114-128. doi: 10.1016/j.psyneuen.2014.04.015

Nelson, H. D., Humphrey, L. L., Nygren, P., Teutsch, S. M., and Allan, J. D. (2002). Postmenopausal hormone replacement therapy: scientific review. JAMA 288, 872-881. doi: 10.1001/jama.288.7.872

Newhouse, P. A., Dumas, J., Hancur-Bucci, C., Naylor, M., Sites, C. K., Benkelfat, C., et al. (2008). Estrogen administration negatively alters mood following monoaminergic depletion and psychosocial stress in postmenopausal women. Neuropsychopharmacology 33, 1514-1527. doi: 10.1038/sj.npp. 1301530

Newhouse, P. A., Dumas, J., Wilkins, H., Coderre, E., Sites, C. K., Naylor, M., et al. (2010). Estrogen treatment impairs cognitive performance after psychosocial stress and monoamine depletion in postmenopausal women. Menopause 17, 860-873. doi: 10.1097/gme.0b013e3181e15df4

Norbury, R., Travis, M. J., Erlandsson, K., Waddington, W., Ell, P. J., and Murphy, D. G. (2007). Estrogen therapy and brain muscarinic receptor density in healthy females: a SPET study. Horm. Behav. 51, 249-257. doi: 10.1016/j.yhbeh.2006.10.007
Ohkura, T., Teshima, Y., Isse, K., Matsuda, H., Inoue, T., Sakai, Y., et al. (1995). Estrogen increases cerebral and cerebellar blood flows in postmenopausal women. J. North Am. Menopause Soc. 2, 13-18.

Owens, J. F., Matthews, K. A., and Everson, S. A. (2002). Cognitive function effects of suppressing ovarian hormones in young women. Menopause 9, 227-235. doi: 10.1097/00042192-200207000-00003

Persad, C. C., Zubieta, J. K., Love, T., Wang, H., Tkaczyk, A., and Smith, Y. R. (2009). Enhanced neuroactivation during verbal memory processing in postmenopausal women receiving short-term hormone therapy. Fertil. Steril. 92, 197-204. doi: 10.1016/j.fertnstert.2008.04.040

Pruis, T. A., Roalf, D. R., and Janowsky, J. S. (2009). Hormone therapy does not modify emotion-induced brain activity in older women. Horm. Behav. 56, 539-547. doi: 10.1016/j.yhbeh.2009.09.008

Rasetti, R., and Weinberger, D. R. (2011). Intermediate phenotypes in psychiatric disorders. Curr. Opin. Genet. Dev. 21, 340-348. doi: 10.1016/j.gde.2011.02.003

Rasgon, N. L., Geist, C. L., Kenna, H. A., Wroolie, T. E., Williams, K. E., and Silverman, D. H. (2014). Prospective randomized trial to assess effects of continuing hormone therapy on cerebral function in postmenopausal women at risk for dementia. PLoS ONE 9:e89095. doi: 10.1371/journal.pone.0089095

Rasgon, N. L., Silverman, D., Siddarth, P., Miller, K., Ercoli, L. M., Elman, S., et al. (2005). Estrogen use and brain metabolic change in postmenopausal women. Neurobiol Aging 26, 229-235. doi: 10.1016/j.neurobiolaging.2004. 03.003

Rasgon, N. L., Small, G. W., Siddarth, P., Miller, K., Ercoli, L. M., Bookheimer, S. Y., et al. (2001). Estrogen use and brain metabolic change in older adults. A preliminary report. Psychiatry Res. 107, 11-18. doi: 10.1016/S0925-4927(01)00084-1

Resnick, S. M., Maki, P. M., Golski, S., Kraut, M. A., and Zonderman, A. B. (1998). Effects of estrogen replacement therapy on PET cerebral blood flow and neuropsychological performance. Horm. Behav. 34, 171-182. doi: 10.1006/hbeh.1998.1476

Riecher-Rössler, A., and Kulkarni, J. (2011). "Biological basis of sex differences in psychopharmacology," in Current Topics in Behavioral Neurosciences, eds J. C. Neill and J. Kulkarni (Berlin; Heidelberg: Springer-Verlag), v-vii.

Robertson, D. M., van Amelsvoort, T., Daly, E., Simmons, A., Whitehead, M., Morris, R. G., et al. (2001). Effects of estrogen replacement therapy on human brain aging: an in vivo $1 \mathrm{H}$ MRS study. Neurology 57, 2114-2117. doi: 10.1212/WNL.57.11.2114

Rocca, W. A., Grossardt, B. R., and Shuster, L. T. (2014). Oophorectomy, estrogen, and dementia: a 2014 update. Mol. Cell. Endocrinol. 389, 7-12. doi: 10.1016/j.mce.2014.01.020

Sanchez, M. G., Morissette, M., and Di Paolo, T. (2013). Oestradiol modulation of serotonin reuptake transporter and serotonin metabolism in the brain of monkeys. J. Neuroendocrinol. 25, 560-569. doi: 10.1111/jne.12034

Shafir, T., Love, T., Berent-Spillson, A., Persad, C. C., Wang, H., Reame, N. K., et al. (2012). Postmenopausal hormone use impact on emotion processing circuitry. Behav. Brain Res. 226, 147-153. doi: 10.1016/j.bbr.2011.09.012

Shaywitz, S. E., Shaywitz, B. A., Pugh, K. R., Fulbright, R. K., Skudlarski, P., Mencl, W. E., et al. (1999). Effect of estrogen on brain activation patterns in postmenopausal women during working memory tasks. JAMA 281, 1197-1202. doi: 10.1001/jama.281.13.1197

Sherwin, B. B., and Henry, J. F. (2008). Brain aging modulates the neuroprotective effects of estrogen on selective aspects of cognition in women: a critical review. Front. Neuroendocrinol. 29, 88-113. doi: 10.1016/j.yfrne.2007.08.002

Sherwin, B. B., and Tulandi, T. (1996). "Add-back" estrogen reverses cognitive deficits induced by a gonadotropin-releasing hormone agonist in women with leiomyomata uteri. J. Clin. Endocrinol. Metab. 81, 2545-2549.

Shively, C. A., and Bethea, C. L. (2004). Cognition, mood disorders, and sex hormones. ILAR J. 45, 189-199. doi: 10.1093/ilar.45.2.189

Silverman, D. H., Geist, C. L., Kenna, H. A., Williams, K., Wroolie, T., Powers, B., et al. (2011). Differences in regional brain metabolism associated with specific formulations of hormone therapy in postmenopausal women at risk for AD. Psychoneuroendocrinology 36, 502-513. doi: 10.1016/j.psyneuen.2010. 08.002

Slopien, R., Junik, R., Meczekalski, B., Halerz-Nowakowska, B., Maciejewska, M., Warenik-Szymankiewicz, A., et al. (2003). Influence of hormonal replacement therapy on the regional cerebral blood flow in postmenopausal women. Maturitas 46, 255-262. doi: 10.1016/S0378-5122(03)00144-0

Smith, Y. R., Bowen, L., Love, T. M., Berent-Spillson, A., Frey, K. A., Persad, C. C., et al. (2011). Early initiation of hormone therapy in menopausal women 
is associated with increased hippocampal and posterior cingulate cholinergic activity. J. Clin. Endocrinol. Metab. 96, E1761-E1770. doi: 10.1210/jc.2011-0351

Smith, Y. R., Love, T., Persad, C. C., Tkaczyk, A., Nichols, T. E., and Zubieta, J. K. (2006). Impact of combined estradiol and norethindrone therapy on visuospatial working memory assessed by functional magnetic resonance imaging. J. Clin. Endocrinol. Metab. 91, 4476-4481. doi: 10.1210/jc.2006-0907

Smith, Y. R., Minoshima, S., Kuhl, D. E., and Zubieta, J. K. (2001). Effects of long-term hormone therapy on cholinergic synaptic concentrations in healthy postmenopausal women. J. Clin. Endocrinol. Metab. 86, 679-684. doi: 10.1210/jcem.86.2.7222

Soares, C. N. (2013). Depression in peri- and postmenopausal women: prevalence, pathophysiology and pharmacological management. Drugs Aging 30, 677-685. doi: 10.1007/s40266-013-0100-1

Stein, P., Baldinger, P., Kaufmann, U., Christina, R. M., Hahn, A., Hoflich, A., et al. (2014). Relation of progesterone and DHEAS serum levels to 5-HT1A receptor binding potential in pre- and postmenopausal women. Psychoneuroendocrinology 46, 52-63. doi: 10.1016/j.psyneuen.2014.04.008

Sumner, B. E., and Fink, G. (1997). The density of 5-hydoxytryptamine2A receptors in forebrain is increased at pro-oestrus in intact female rats. Neurosci. Lett. 234, 7-10. doi: 10.1016/S0304-3940(97)00651-4

Sumner, B. E., and Fink, G. (1998). Testosterone as well as estrogen increases serotonin2A receptor mRNA and binding site densities in the male rat brain. Brain Res. Mol. Brain Res. 59, 205-214. doi: 10.1016/S0169-328X(98)00148-X

Sumner, B. E., Grant, K. E., Rosie, R., Hegele-Hartung, C., Fritzemeier, K. H., and Fink, G. (1999). Effects of tamoxifen on serotonin transporter and 5hydroxytryptamine(2A) receptor binding sites and mRNA levels in the brain of ovariectomized rats with or without acute estradiol replacement. Brain Res. Mol. Brain Res. 73, 119-128. doi: 10.1016/S0169-328X(99)00243-0

Sumner, B. E., Grant, K. E., Rosie, R., Hegele-Hartung, C., Fritzemeier, K. H., and Fink, G. (2007). Raloxifene blocks estradiol induction of the serotonin transporter and 5-hydroxytryptamine2A receptor in female rat brain. Neurosci. Lett. 417, 95-99. doi: 10.1016/j.neulet.2007.02.039

Tayebati, S. K., and Amenta, F. (2013). Choline-containing phospholipids: relevance to brain functional pathways. Clin. Chem. Lab. Med. 51, 513-521. doi 10.1515/cclm-2012-0559

Tinkler, G. P., Tobin, J. R., and Voytko, M. L. (2004). Effects of two years of estrogen loss or replacement on nucleus basalis cholinergic neurons and cholinergic fibers to the dorsolateral prefrontal and inferior parietal cortex of monkeys. J. Comp. Neurol. 469, 507-521. doi: 10.1002/cne.11028

Toffol, E., Heikinheimo, O., and Partonen, T. (2013). Associations between psychological well-being, mental health, and hormone therapy in perimenopausal and postmenopausal women: results of two population-based studies. Menopause 20, 667-676. doi: 10.1097/gme.0b013e318278eec1

Toffoletto, S., Lanzenberger, R., Gingnell, M., Sundstrom-Poromaa, I., and Comasco, E. (2014). Emotional and cognitive functional imaging of estrogen and progesterone effects in the female human brain: A systematic review. Psychoneuroendocrinology 50C, 28-52. doi: 10.1016/j.psyneuen.2014.07.025

Voytko, M. L. (2002). Estrogen and the cholinergic system modulate visuospatial attention in monkeys (Macaca fascicularis). Behav. Neurosci. 116, 187-197. doi: 10.1037/0735-7044.116.2.187
Voytko, M. L., Tinkler, G. P., Browne, C., and Tobin, J. R. (2009). Neuroprotective effects of estrogen therapy for cognitive and neurobiological profiles of monkey models of menopause. Am. J. Primatol. 71, 794-801. doi: 10.1002/ajp. 20705

Wharton, W., Gleason, C. E., Olson, S. R., Carlsson, C. M., and Asthana, S. (2012). Neurobiological underpinnings of the estrogen - mood relationship. Curr. Psychiatry Rev. 8, 247-256. doi: 10.2174/157340012800792957

Wihlback, A. C., Sundstrom-Poromaa, I., Allard, P., Mjorndal, T., Spigset, O., and Backstrom, T. (2001). Influence of postmenopausal hormone replacement therapy on platelet serotonin uptake site and serotonin 2A receptor binding. Obstet. Gynecol. 98, 450-457. doi: 10.1016/S0029-7844(01)01461-2

Wnuk, A., Korol, D. L., and Erickson, K. I. (2012). Estrogens, hormone therapy, and hippocampal volume in postmenopausal women. Maturitas 73, 186-190. doi: 10.1016/j.maturitas.2012.07.001

Yaffe, K., Lindquist, K., Sen, S., Cauley, J., Ferrell, R., Penninx, B., et al. (2009). Estrogen receptor genotype and risk of cognitive impairment in elders: findings from the Health ABC study. Neurobiol. Aging 30, 607-614. doi: 10.1016/j.neurobiolaging.2007.08.003

Yaffe, K., Lui, L. Y., Grady, D., Stone, K., and Morin, P. (2002). Estrogen receptor 1 polymorphisms and risk of cognitive impairment in older women. Biol. Psychiatry 51, 677-682. doi: 10.1016/S0006-3223(01)01289-6

Yaffe, K., Sawaya, G., Lieberburg, I., and Grady, D. (1998). Estrogen therapy in postmenopausal women: effects on cognitive function and dementia. JAMA 279, 688-695. doi: 10.1001/jama.279.9.688

Yue, Y., Hu, L., Tian, Q. J., Jiang, J. M., Dong, Y. L., Jin, Z. Y., et al. (2007) Effects of long-term, low-dose sex hormone replacement therapy on hippocampus and cognition of postmenopausal women of different apoE genotypes. Acta Pharmacol. Sin. 28, 1129-1135. doi: 10.1111/j.1745-7254.2007. 00618.x

Zweifel, J. E., and O'Brien, W. H. (1997). A meta-analysis of the effect of hormone replacement therapy upon depressed mood. Psychoneuroendocrinology 22, 189-212. doi: 10.1016/S0306-4530(96)00034-0

Conflict of Interest Statement: The authors declare that the research was conducted in the absence of any commercial or financial relationships that could be construed as a potential conflict of interest.

Received: 21 July 2014; accepted: 12 November 2014; published online: 08 December 2014.

Citation: Comasco E, Frokjaer VG and Sundström-Poromaa I (2014) Functional and molecular neuroimaging of menopause and hormone replacement therapy. Front. Neurosci. 8:388. doi: 10.3389/fnins.2014.00388

This article was submitted to Neuroendocrine Science, a section of the journal Frontiers in Neuroscience.

Copyright (c) 2014 Comasco, Frokjaer and Sundström-Poromaa. This is an openaccess article distributed under the terms of the Creative Commons Attribution License (CC BY). The use, distribution or reproduction in other forums is permitted, provided the original author(s) or licensor are credited and that the original publication in this journal is cited, in accordance with accepted academic practice. No use, distribution or reproduction is permitted which does not comply with these terms. 


\section{APPENDIX \\ ACRONYMS/ABBREVIATIONS IN THE TABLES}

aC: anterior cingulate; aCC: anterior cingulate cortex; AChE: acetylcholinesterase; BS: brain stem; Cau: caudate; Cb: cerebellum; CEE: conjugated equine estrogen; CER: cerebellar cortex; CG: cingulate gyrus; $\mathrm{Cn}$ : caudate nucleus; Cun: cuneus; daCC: dorsal anterior cingulate cortex; dlFC: dorsolateral frontal cortex; dFG: dorsal frontal gyrus; dlPFC: dorsolateral prefrontal cortex; EC: entorhinal cortex; E: estrogen; FC: frontal cortex; FDG: fluorodeoxyglucose; FG: frontal gyrus; FL: frontal lobe; FP: follicular phase; FuG: fusiform gyrus; gr: group; HC: hippocampus; HERA: hemisphere encoding retrieval assimetry; HG: hippocampal gyrus; HMPAO: hexamethylpropylene-amino oxime; HT: hormonal treatment $(\mathrm{E}+\mathrm{P})$; Hy: hypothalamus; $\mathrm{iF}$ : inferior frontal; iFC: inferior frontal cortex; iFG: inferior frontal gyrus; Ins: insula; ipFG; inferior posterior frontal gyrus; iPL: inferior parietal lobe; iTG: inferior temporal gyrus; iTL: inferior temporal lobe; LgG: lingual gyrus; Ln: lentiform nucleus; lOFC: lateral orbito frontal cortex; mAChR: muscarinic acetylcholine receptors; MB: mammillary body; MF: medial frontal; mesial-TR: mesial temporal region; mFC: medical frontal cortex; meFG: medial frontal gyrus; meOFC: medial orbitofrontal cortex; meOG: medial occipital gyrus; miF: middle frontal; miFG: middle frontal gyrus; mFL: medial frontal lobe; miTG: middle temporal gyrus; MP: menopause; n: number of individuals; Neg: negative pictures; Neu: neutral pictures; NT: no treatment; OC: occipital cortex; oF: orbital frontal; OFC: orbitofrontal cortex; OL: occipital lobe; P: progesterone/progestins; pC: posterior cingulate; PC: parietal cortex; pCC: posterior cingulate cortex; PCL: paracentral lobule; pgG: postcentral gyrus; pCun: precuneus; paracL: paracentral lobule; $\mathrm{PHG}$ : parahippocampal gyrus; PL: parietal lobe; pgACC: pregenual anterior cingulate cortex; pIns: posterior insula; pCG: posterior cingulate gyrus; PFC: prefrontal cortex; PL: parietal lobe; Pos: positive pictures; post-cG: postcentral gyrus; pPHG: posterior para-hippocampal gyrus; pre-cG: precentral gyrus; Pu: putamen; rCMRglc: regional cerebral glucose metabolism; sF: superior frontal; sFG: superior frontal gyrus; smG: supra-marginal gyri; sPC: superior parietal cortex; sTG: superior temporal gyrus; STRAW: Stages of Reproductive Aging Workshop [ranging from -5 to +2 ] (Harlow et al., 2012); TC: temporal cortex; TD: tryptophan depletion; thal: thalamus; TL: temporal lobe; TP: temporal pole; TR: temporal region; VAChT: vesicular acetylcholine transporter; vlPFC: ventrolateral prefrontal cortex; vpTL: ventral posterior temporal lobe.

${ }^{a}$ SEM: standard error of the mean. 